\title{
Integration of chlorogenic acid recovery and bioethanol production from spent coffee grounds
}

Burniol Figols, Anna; Cenian, Katarzyna; Skiadas, Ioannis V.; Gavala, Hariklia N.

\section{Published in:}

Biochemical Engineering Journal

Link to article, DOI:

10.1016/j.bej.2016.04.025

Publication date:

2016

Document Version

Peer reviewed version

Link back to DTU Orbit

\section{Citation (APA):}

Burniol Figols, A., Cenian, K., Skiadas, I. V., \& Gavala, H. N. (2016). Integration of chlorogenic acid recovery and bioethanol production from spent coffee grounds. Biochemical Engineering Journal, 116, 54-64. https://doi.org/10.1016/j.bej.2016.04.025

\section{General rights}

Copyright and moral rights for the publications made accessible in the public portal are retained by the authors and/or other copyright owners and it is a condition of accessing publications that users recognise and abide by the legal requirements associated with these rights.

- Users may download and print one copy of any publication from the public portal for the purpose of private study or research.

- You may not further distribute the material or use it for any profit-making activity or commercial gain

- You may freely distribute the URL identifying the publication in the public portal 


\section{Title}

Integration of chlorogenic acid recovery and bioethanol production from spent coffee grounds.

\section{Authors}

Anna Burniol-Figolsa,1,*, Katarzyna Ceniana, Ioannis V. Skiadas ${ }^{b}$ and Hariklia N. Gavalab

\section{Affiliations}

aAalborg University Copenhagen, Dept. of Chemistry and Bioscience, Section for Sustainable Biotechnology. A.C. Meyers Vænge 15, 2450 Copenhagen SV (Denmark)

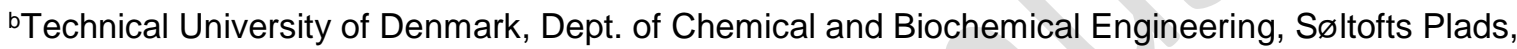
Building 229, 2800 Kgs. Lyngby (Denmark).

\section{Citation}

Burniol-Figols, A., Cenian, K., Skiadas, I. V., \& Gavala, H. N. (2016). Integration of chlorogenic acid recovery and bioethanol production from spent coffee grounds. Biochemical engineering journal, 116, 54-64.

${ }^{1}$ Present address: Technical University of Denmark, Dept. of Chemical and Biochemical Engineering, Center for Bioprocess Engineering. Søltofts Plads, Building 227, 2800 Kgs. Lyngby (Denmark).

*Corresponding author. Email address: afig@kt.dtu.dk, anna.burniol@gmail.com 


\section{Abstract}

Spent coffee grounds (SCG) are an abundant by-product of the coffee industry with a complex composition that makes them a promising feedstock for a biorefinery. The objective of this study was to evaluate SCG as a substrate for combined chlorogenic acid and bioethanol production after dilute acid hydrolysis.

The effect of phenolics extraction on the downstream process was evaluated exhibiting no loss of sugars and an increase in the sugar release efficiency during the dilute acid hydrolysis.

In order to suggest an economically feasible process, phenolics extraction and dilute acid hydrolysis prior to ethanol fermentation were optimised by means of experimental design. The responses of the designs were not only the efficiencies of the processes, but also a balance between product recovery and estimated costs. In both cases, decreased efficiencies obtained with low liquid-solid ratios were countervailed by increased products concentrations and higher economical performance.

Under the optimised conditions, the purity of the phenolics extract (32\%) could allow it to enter the market as a dietary supplement of chlorogenic acid, a product with high trade value. Moreover, a concentration of $3.9 \%(w / v)$ ethanol was reached upon fermentation of the hydrolysate of SCG after extraction and dilute acid hydrolysis.

\section{Graphical abstract}

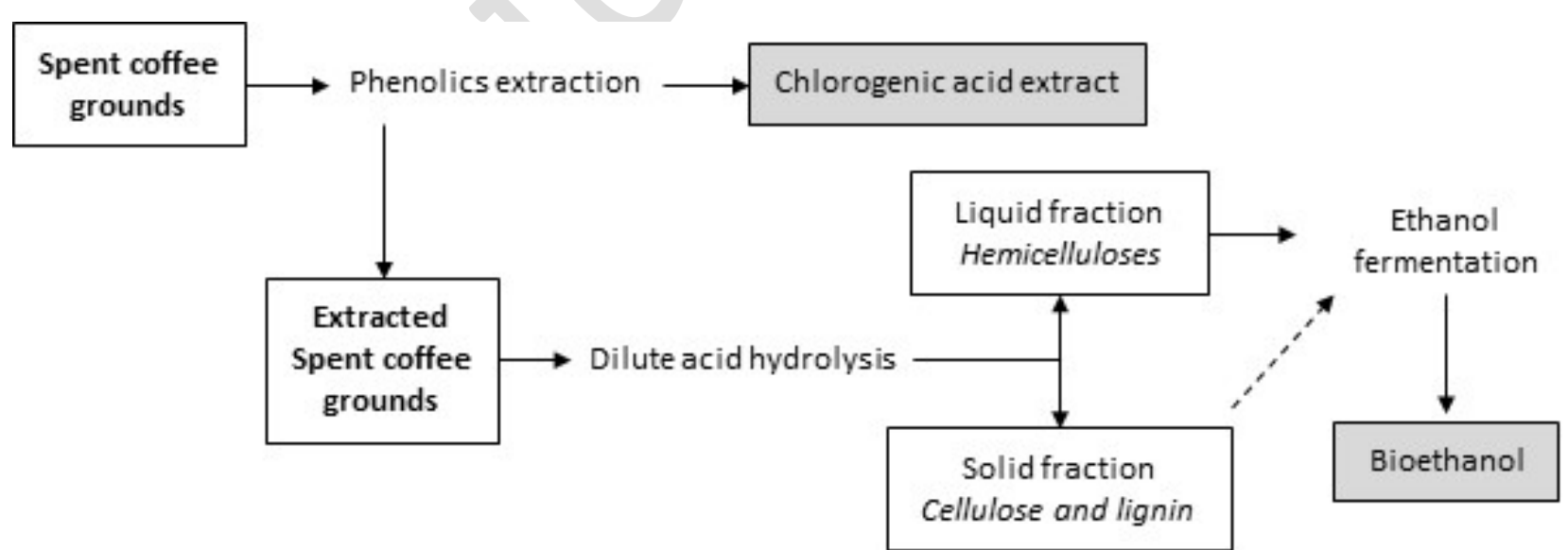




\section{Introduction ${ }^{2}$}

Around 8.6 million tons of coffee were produced in 2014 [1], making it a very important global commodity. Throughout the production of the coffee, several types of waste are generated including spent coffee grounds (SCG) obtained after brewing the coffee beans both for direct consumption and for production of instant coffee. Given that around $2 \mathrm{Kg}$ of wet SCG are generated per each $\mathrm{Kg}$ of coffee processed [2], the magnitude of this by-product is remarkable. Since the 1980s, combustion is the most common way to utilise spent coffee grounds, given its high calorific value [3]. However, the composition of SCG (Table 1), which is rich in carbohydrates, lipids and phenolic compounds, has motivated an increasing interest to develop processes in order to exploit the various fractions of this residue and add more value to the production chain $[2,4]$.

Table 1. Main reported components of green coffee beans and spent coffee grounds. References are provided in brackets.

\begin{tabular}{|c|c|c|}
\hline (Dry matter \%) & $\begin{array}{c}\text { Green coffee } \\
\text { bean }\end{array}$ & $\begin{array}{l}\text { Spent coffee } \\
\text { grounds }\end{array}$ \\
\hline Carbohydrates & $48-61[5,6]$ & $45-47[7,8]$ \\
\hline Cellulose & $7.8[6]$ & $8.6-9.0[7,8]$ \\
\hline Hemicellulose & $40[6]$ & $37-38[7,8]$ \\
\hline Mannose & $22[6]$ & $23-26[7,8]$ \\
\hline Galactose & $12[6]$ & $15[7,8]$ \\
\hline Arabinose & $4[6]$ & $1.4-1.9[7,8]$ \\
\hline Lipids & $10-16[5]$ & $9-16$ [9] \\
\hline Proteins & $10[5]$ & $13-17[7,9]$ \\
\hline Total polyphenols & $<14[10]$ & $1.7-3.5[11]$ \\
\hline Chlorogenic acids & $4-14[5,10,12]$ & $0.1-0.8[9,11]$ \\
\hline Caffeine & $1-2[5,12]$ & $0.5-1.2[9,11]$ \\
\hline
\end{tabular}

Almost $50 \%$ of the SCG dry mass corresponds to carbohydrates and most of them are hexose sugars as part of the hemicellulosic material (mannose and galactose) (Table 1). This constitutes a great advantage over

\section{${ }^{2}$ Abbreviations}

CGA: Chlorogenic acid; CGA eq.: Chlorogenic acid equivalents; CQA: Caffeoylquinic acid; HMF: hydroxymethylfurfural; $\mathrm{HC} \_\mathrm{H}$ : High concentrated hydrolysate; LC_H: Low concentrated hydrolysate; HC_S; High concentrated slurry; LC_S: Low concentrated slurry; L/S ratio: Liquid-solid ratio; SCG: Spent coffee grounds; SCGE: Spent coffee grounds after phenolics extraction; SCGH: Solid fraction of spent coffee grounds after phenolics extraction and dilute acid hydrolysis; TSS: Total suspended solids, TS: Total solids; VS: Volatile solids; WIS: Water insoluble solids. 
Burniol-Figols, A., Cenian, K., Skiadas, I. V., \& Gavala, H. N. (2016). Integration of chlorogenic acid recovery and bioethanol production from spent coffee grounds. Biochemical engineering journal, 116, 54-64.

other lignocellulosic substrates given that most of the easily biodegradable sugars can be released in a single step using mild pre-treatments such as dilute acid hydrolysis. First attempts on testing spent coffee grounds as feedstock for bioethanol production have been recently documented $[8,13-15]$.

Green coffee beans are an important source of phenolics compounds (Table 1), with chlorogenic acids being the most abundant family. Its main representative is 5-O-caffeoylquinic acid (5-CQA), which the denomination chlorogenic acid (CGA) generally refers to. This compound has potential applications as antioxidant, food preservative and various medical treatments [16]. Moreover, it has already a commercial application in the form of weight loss dietary supplements containing green coffee beans extract such as Svetol® $[17]$.

Given that part of the phenolic compounds are still present in spent coffee grounds this residue has been suggested as a sustainable alternative for phenolics extraction, already tested in laboratory scale using different methods [4] such as liquid-solid extraction [16,18-22], Soxhlet extraction [20] and microwaveassisted extraction [23]. From those methods, liquid-solid extraction arises as a simple and effective method $[18,20]$, and was thus chosen herein.

This study investigates the possibility of producing chlorogenic acid and bioethanol in a biorefinery scheme (Fig.1). After extraction of chlorogenic acid, the remaining solids underwent acid hydrolysis to release the hemicellulose sugars, which were further fermented into bioethanol. With this strategy, both the phenolics and the carbohydrate fraction would be exploited. Moreover, the inclusion of a high value product could contribute to the economic viability of bioethanol production from SCG.

First of all, the effect of the extraction process on the dilute acid hydrolysis was studied, focusing on the possible loss of sugars and the effect of the sugar release efficiency. Then, both the extraction and the dilute acid hydrolysis were studied using experimental design methodology. In both cases, the objective was not only to study the effect of the different parameters on the efficiency, but to suggest values that would be reasonable from an economic point of view. Special focus was put on the liquid-solid ratio, as a factor dramatically affecting the product concentration and the downstream costs. Thus, an additional response balancing the product recovery and the expected income with the estimated process costs was calculated and the model arising from it was used to choose the parameter values.

The recovery efficiency was validated with the chosen values of the parameters and the concentration and purity of the products (chlorogenic acid and ethanol) discussed. 


\section{Materials and methods}

\subsection{Biomass}

Spent coffee grounds (SCG) were obtained from a coffee machine Wittenborg model 7100 B2C. The coffee was a mixture of Arabica roasted coffees provided by Frellsen Kaffe (Frellsen Rød). Noteworthy to say, two batches of SCG were utilised throughout the experiments. Characterisation of the first batch (used in section 3.1) was the following: TS: $46.6 \%(w / w)$, total sugars: $42.0 \mathrm{~g} / 100 \mathrm{~g}$ TS (\% of the total sugars: glucose 17.0\% and hemicelluloses 83.0\%). For the second batch (used for sections 3.2 and 3.3), the figures were: TS: 45.9\% (w/w), total sugars: $50.1 \mathrm{~g} / 100 \mathrm{~g}$ TS (\% of the total sugars: glucose $17.5 \%$, hemicelluloses $82.5 \%$, mannose 57\%, galactose $20 \%$ and arabinose $5 \%$ ).

\subsection{Analytical methods}

Total solids (TS), volatile solids (VS) and total suspended solids (0.7 $\mu \mathrm{m})$ (TSS) were determined as described in Sluiter et al. [24]. Total structural sugars of biomass were determined in duplicate with the protocol described in Sluiter et al. [25]. Soluble sugars content in the liquid fraction was assessed by dilute acid hydrolysis according to Bjerre et al. [26]. HPLC analysis of sugars, ethanol, furfural and hydroxymethylfurfural (HMF) was done as reported in Baroi et al. [27]. Noteworthy, peaks for mannose and galactose overlapped in the HPLC chromatogram and were discriminated using an independent assay (Megazymes K-ARGA).

Total phenolic content of the extracts was estimated by the Folin Ciocalteu method using the proportions described in Pinelo et al. [19], but with a total volume of $200 \mu \mathrm{L}$ in 96 well plates. Readings were done at 765 $\mathrm{nm}$ after two hours of incubation and by mixing $200 \mu \mathrm{L}$ of the reaction with $800 \mu \mathrm{L}$ of water. In specific experiments, absorbance at $325 \mathrm{~nm}$ was also used as indicative of chlorogenic acid concentration [28]. Chlorogenic acid (5-O-caffeoylquinic acid) was used as standard for both assays. Samples were analysed using technical duplicates.

\subsection{Effect of chlorogenic acid extraction on the downstream processes}

The experimentation included three main steps: extraction, hydrolysis and fermentation. Extraction was carried out at $70^{\circ} \mathrm{C}$ using $40 \mathrm{~g}$ of raw SCG with a liquid-solid (L/S) ratio of $25 \mathrm{~mL}$ solvent/g TS. Ethanol $60 \%$ (v/v) was used as a solvent. After extraction, solid-liquid separation was done by vacuum filtration (Whatman 1003-185) and the cake was washed with $150 \mathrm{~mL}$ of distilled water and dried overnight at $45^{\circ} \mathrm{C}$ to remove 
residual solvent. Free and soluble sugars in the extracts were quantified to evaluate sugar loss during this step.

Hydrolysis was performed both on extracted SCG (SCGE) (TS 95\% w/w) and non-extracted SCG (TS $46.6 \% \mathrm{w} / \mathrm{w}$ ) for comparison purposes. The procedure was done as optimised in Mussatto et al. [7] with some modifications: $1 \% \mathrm{H}_{2} \mathrm{SO}_{4}\left(\mathrm{w} / \mathrm{w}\right.$ ) with a liquid-solid (L/S) ratio of $10 \mathrm{~g}$ liquid/g TS and $45 \mathrm{~min}$ at $140^{\circ} \mathrm{C}$ in the autoclave.

The liquid hydrolysates obtained after solid-liquid separation (vacuum filtration Whatman 1003-185) were analysed for sugars concentration and total phenols (Folin Ciocalteu) and the sugar release efficiency was calculated as g sugar released per gram of dry SCG/SCGE based on the sugar compositional analysis of both solids. The different moisture contained in the solids was taken into account for the calculations. As a clarification, the hydrolysate obtained under these conditions is later on referred as low concentrated hydrolysate (LC_H) for comparison purposes.

Ethanolic fermentations were run as described in section 2.5. The whole procedure was executed in experimental triplicates while HPLC analysis was performed just in two of the triplicates. Liquid recovery was assessed after solid-liquid separations of the three replicates.

\subsection{Experimental designs}

Two experimental designs were performed in this study, one related to the chlorogenic acid extraction and another concerning the dilute acid hydrolysis. In both cases, a Central Composite design was employed, which uses a $2^{k}$ factorial nucleus (cube points), $2 \cdot k$ axial points and a duplicate central point, where $k$ is the number of factors/parameters to be analysed. Real variable values $(X)$ are given dimensionless values $(x)$ from -1 to 1 where 0 is the central point [29].

Slightly different designs were applied in the two cases. For chlorogenic acid extraction, a two-factor circumscribed central composite design was applied, with axial points at $\alpha=2^{k / 4}$ from the central point. For acid hydrolysis evaluation, the design of election was a face-centered design with 3 factors where axial points were studied within the central cube. Although this compromises the rotability of the model, optimal axial points were physically impossible to study.

The factors analysed in the chlorogenic acid design were the time (10-50 $\mathrm{min})$ and the $\mathrm{L} / \mathrm{S}$ ratio $(10-40 \mathrm{~mL}$ solvent /g TS) (Table 2). For the second design, the factors evaluated were the time (20-70 min), the L/S ratio (3.5-10 g liquid / g TS) and the sulphuric acid concentration (0.5-3.5 \% w/w) (Table 4). Noteworthy to say, the $\mathrm{L} / \mathrm{S}$ ratios are expressed in different units in the two experimental designs for a better comparison with 
literature results. Each of the experimental points was tested in duplicate giving a total of 20 and 32 assays respectively. Apart from the experimental responses (described in Tables 2 and 4) both experimental designs included cost estimation of each one of the experimental points as an additional response of the statistical model.

Coefficients for linear, quadratic and interaction effects for each of the variables on the responses were calculated by regression and significance was assessed by Student's $t$-test $(p=0.05)$. The model significance was assessed by ANOVA. Design and analysis were performed using Design expert v.10.

\subsubsection{Chlorogenic acid extraction and economic calculations}

The total volume of the experimental assays was fixed at $40 \mathrm{~mL}$ of $60 \%(\mathrm{v} / \mathrm{v})$ ethanol mixed with the appropriate amount of raw SCG in Pyrex tubes. Samples were placed horizontally in an incubator at $70^{\circ} \mathrm{C}$ and $150 \mathrm{rpm}$ and removed at the desired time. After incubation, samples were centrifuged at $2500 \mathrm{~g}$ for $10 \mathrm{~min}$ at $4^{\circ} \mathrm{C}$ and the supernatant was filtered through $0.45 \mu \mathrm{m}$ filters and kept at $-20^{\circ} \mathrm{C}$ for phenols determinations. The total solids of the solutions were determined from fresh extracts and were used for the calculation of the purity.

Estimation of the cost of each one of the treatments was done considering the cost of the solvent used, the energy needs of the extraction and the energy needs of the evaporation. These costs were balanced with the estimated incomes from the extract commercialization.

The cost of ethanol was estimated at $0.69 \$ / L$ (2.6 \$/gal), based on recorded and predicted prices for ethanol fuel [30]. Reuse of the solvent after evaporation was considered with $85 \%$ efficiency. The energy needs of the extraction were calculated considering only the energy needed to heat the respective volume of solvent from $25^{\circ} \mathrm{C}$ to $70^{\circ} \mathrm{C}$. A loss of temperature from $70^{\circ} \mathrm{C}$ to $50^{\circ} \mathrm{C}$ was assumed during the liquid-solid separation taking place before the evaporation of the solvent.

Heating oil was considered as the energy source as this is the main source of energy in Brazil [31] and its price was estimated at $1.54 \$$ /gal [32]. This country was chosen for being among the major producers of both ethanol and coffee. The price of the evaporated extract with a minimum concentration of $30 \%$ CGA equivalents was estimated in $40 \$ / \mathrm{Kg}$ (SVAgrofood, personal communication). All extracts were attributed this value as none of them reached $45 \%$, which is the next commercialised purity grade. 


\subsubsection{Dilute acid hydrolysis and economic calculations}

Before acid hydrolysis, phenolic compounds were extracted from SCG at the optimal conditions found in section $3.2(10 \mathrm{~mL} / \mathrm{g}$ TS and a time of $40 \mathrm{~min})$. The different experimental assays were performed in $60 \mathrm{~mL}$ Pyrex tubes with $10 \mathrm{~g}$ dilute acid solution and the correspondent amount of dried solids (SCGE). Tubes were autoclaved at $140^{\circ} \mathrm{C}$ and allowed to cool down at room temperature. After that, the content was centrifuged 10 min at $10000 \mathrm{~g}$. Supernatants were kept at $-20^{\circ} \mathrm{C}$ before HPLC analysis of sugars, ethanol, furfural and hydroxymethylfurfural (HMF) and phenols determination by UV-Vis Spectrophotometry. Sugar release efficiency was calculated based on the carbohydrate composition of SCGE, determined by strong acid hydrolysis.

Economic assessment of the effect of the L/S ratio was performed as a balance of the cost of the pretreatment reactor and the ethanol income. The assessment was contextualised in a soluble coffee production plant with an annual production of 25550 tonnes / year (Cacique ${ }^{\circledR}$, Paraná, Brazil). The volume of the hydrolysis reactor was calculated dividing the annual SCG production in one batch per day and using the respective L/S ratio. The reaction volume was considered to be $90 \%$ of the size of the reactor. The cost was assessed based on assumptions of Wooley et al. [33]. The cost of the reactor was scaled based on volume units with a sizing exponent of 0.78 and the price updated to 2014 with the consumer price index increment . The annual cost impact of the capital investment was estimated on a 20 years life and an installation factor of 1.5. The annual maintenance costs were estimated at $2 \%$ of the capital investment [33]. The ethanol production was calculated based on the measured C6 sugars released in each one of the scenarios with an ethanol conversion of $90 \%$ of the theoretical value. Income was calculated with an ethanol price of $0.69 \$ / L$ [30].

\subsection{Comparison with the commercial chlorogenic acid extract}

One tablet of Green Coffee extract containing Svetol® (Natures Aid, UK) was dissolved in MilliQ water to the same total solids concentration as the extract obtained at the optimised conditions of the extraction (10 $\mathrm{mL} / \mathrm{g}$ TS and a time of $40 \mathrm{~min}$ ) and used for chlorogenic acid determination (by Folin Ciocalteu and UV Abs $325 \mathrm{~nm}$ methods).

Caffeine extraction was performed by a chloroform liquid-liquid extraction. The ethanol contained in 16.5 $\mathrm{mL}$ of extract in tubes was allowed to evaporate at $75^{\circ} \mathrm{C}$ and the tubes were refilled with water up to $40 \mathrm{~mL}$. Then $8 \mathrm{~mL}$ of the aqueous solution was extracted 3 times with $500 \mu \mathrm{L}$ of chloroform, removing the chloroform 
Burniol-Figols, A., Cenian, K., Skiadas, I. V., \& Gavala, H. N. (2016). Integration of chlorogenic acid recovery and bioethanol production from spent coffee grounds. Biochemical engineering journal, 116, 54-64.

fraction after each step. Chlorogenic acid was measured in the obtained aqueous solution. Spiked samples were used for assessing the recovery of chlorogenic acid.

\subsection{Ethanol fermentations}

Ethanol fermentations were done by Saccharomyces cerevisiae strain obtained from Gær Malteserkors. $60 \mathrm{~mL}$ of hydrolysate ( $\mathrm{pH}$ was adjusted to 5.5 with $\mathrm{NaOH}$ pellets) were autoclaved at $121^{\circ} \mathrm{C}$ for 20 min after sparging with $\mathrm{N}_{2}$ and $\mathrm{CO}_{2}$ (80\%:20\%) in rubber sealed bottles and were inoculated with $1 \mathrm{~g} / \mathrm{L}$ of pre-grown culture. Incubation was done at $30^{\circ} \mathrm{C}$ with $150 \mathrm{rpm}$ agitation. For the pre-grown cultures, single colonies were inoculated into a liquid medium consisting of $3 \mathrm{~g} / \mathrm{L}$ of $\left(\mathrm{NH}_{4}\right)_{2} \mathrm{HPO}_{4}, 1 \mathrm{~g} / \mathrm{L}$ of $\mathrm{MgSO}_{4} \cdot 7 \mathrm{H}_{2} \mathrm{O}, 3 \mathrm{~g} / \mathrm{L}$ of yeast extract and $30 \mathrm{~g} / \mathrm{L}$ of sugars [14]. The sugar solution was a mixture of galactose, mannose and glucose at the same relative proportions as found at the hydrolysate. Fermentations were evaluated in terms of sugars consumption, ethanol production and total suspended solids (TSS) increase as a measurement of cell growth. In some of the experiments, gas production measured by water displacement at discrete time points was used as an indirect measurement of metabolic activity.

Two types of hydrolysates were used: the low concentration hydrolysate (LC_H) obtained at the conditions mentioned in section $2.2\left(10 \mathrm{~g}\right.$ liquid/g TS, $1 \% \mathrm{H}_{2} \mathrm{SO}_{4}(\mathrm{w} / \mathrm{w})$ and 45 minutes) and the high concentration hydrolysate $\left(\mathrm{HC} \_\mathrm{H}\right)$ obtained at the conditions concluded from the experimental design $(3.5 \mathrm{~g}$ liquid/g TS, $3 \% \mathrm{H}_{2} \mathrm{SO}_{4}(\mathrm{w} / \mathrm{w})$ and 20 minutes). The recovery of the liquid fraction was always assessed after the solid-liquid separation. The residual solids were washed with $3 \mathrm{~L}$ of distilled $\mathrm{H}_{2} \mathrm{O}$ to determine the water insoluble solids (WIS).

In specified cases, solids after the hydrolysis were included in the fermentation, thus skipping the solidliquid separation after the hydrolysis. Those experimental settings are referred to as slurry fermentations: low concentrated slurry (LC_S) obtained after hydrolysis at the conditions mentioned at section 2.2 and high concentration slurry (HC_S) obtained at hydrolysis conditions established after the experimental design.

The fermentation assays were run in triplicates, except HC_S, which was replicated five times since accurate sampling was problematic due to the high concentration of solids. Two of the bottles were opened at sampling times and the remaining three were kept until the experiment was over.

\section{Results and discussion}

\subsection{Effects of the chlorogenic acid extraction on the downstream processes}


Burniol-Figols, A., Cenian, K., Skiadas, I. V., \& Gavala, H. N. (2016). Integration of chlorogenic acid recovery and bioethanol production from spent coffee grounds. Biochemical engineering journal, 116, 54-64.

Several articles studying the effect of different solvents and factors on solid-liquid extraction of phenolic compounds from SCG have been published [11,16,18-22]. Based on those studies, solvent (ethanol $60 \%$ $\mathrm{w} / \mathrm{w})$ and extraction conditions $\left(70^{\circ} \mathrm{C}\right.$ for $\left.10 \mathrm{~min}\right)$ were chosen to evaluate the effects on the subsequent acid hydrolysis and fermentation steps. Under this conditions, phenolics were extracted with an efficiency of $54.6 \pm$ $0.7 \mathrm{mg}$ CGA eq. $/ \mathrm{g}$ TS.

No sugars were detected in the liquid extracts, which was essential for the suggestion of the combined phenolics and sugar exploitation.

In the solid fraction, analysis of sugar composition showed an increase in the sugar percentage from $42 \%$ to $47 \%$ after the extraction, which revealed a second benefit of the combined process. The proportions of the different sugars were maintained. Furthermore, extracted solids presented higher hemicellulose release efficiencies when submitted to dilute acid hydrolysis (98.0\%), compared to the non-extracted SCG (80.6\%) (Fig. $2 \mathrm{~A}$ ), implying that a partial loosening of polymers occurred during the extraction procedure. Cellulose release efficiency and glucose concentration was much lower than for hemicellulose sugars, which is a known fact for dilute acid hydrolysis (further discussed in section 3.3).

Lastly, in order to evaluate the effect of the phenolics extraction on the ethanol fermentation the hydrolysates were fermented using S. cerevisiae, which had a better performance in previous studies on SCG compared to other common ethanol producing microorganisms [14]. Only arabinose was not consumed after $24 \mathrm{~h}$ of fermentation as S. cerevisiae is not able to metabolise C5 sugars. Ethanol concentration reached 14.2 $\mathrm{g} / \mathrm{L}$ in the ethanol extracted hydrolysate, with an ethanol yield of $90 \%$ (Fig. 2 B).

Non-extracted SCG hydrolysate was anticipated to reach a lower ethanol yield due to the higher concentration of phenolic compounds (Fig. 2 A), which are generally recognised as inhibitory for microbial growth $[34,35]$. Nevertheless, the experiments with non-extracted SCG hydrolysate did not result in significantly different ethanol and biomass yields compared to the extracted SCG hydrolysates (Fig. 2 B).

\subsection{Optimisation of chlorogenic acid extraction}

The L/S ratio used for obtaining the resulted presented in section $3.1(25 \mathrm{~mL} / \mathrm{g}$ TS) was in the range of the values reported in previously cited literature. However, the amount of solvent was considered too high from an industrial point of view. Thus, the effect of this factor on the efficiency of the extraction, together with the effect of the time, was studied by means of a central composite experimental design. Also the purity of the extract was evaluated as a response in order to discuss its potential commercialisation. 
Results obtained at the different experimental sets showed lower CGA recovery with lower L/S ratio (Table 2). Quantifications with the UV-absorbance gave lower results than the Folin Ciocalteu method, given the higher specificity of the method, however, the two methods showed the same tendency with decreasing L/S ratio. It is important to emphasize that even though Folin Ciocalteu method is a measurement of total antioxidant/reducing capacity of samples, it is the one used in commercial chlorogenic acid preparations to indicate the concentration of total polyphenols [36]. UV absorbance at 325nm has been used as a more specific method for chlorogenic acids determination $[11,28,37]$. Nonetheless, it is still not completely specific for chlorogenic acids given that other compounds present in smaller amounts in coffee, such as ferulic acid or caffeic acid, also exhibit an absorbance peak at $325 \mathrm{~nm}$ [11].

Table 2. Experimental design of the phenols extraction with the real coded values of the factors (coded dimensionless values in parenthesis) and evaluated responses.

\begin{tabular}{|c|cc|cccc|}
\cline { 2 - 8 } \multicolumn{1}{c|}{} & \multicolumn{2}{c|}{ Factors } & \multicolumn{4}{c|}{ Responses } \\
\hline & \multicolumn{2}{|c|}{ Real value (coded value) } & \multicolumn{2}{c|}{$\begin{array}{c}\text { Chlorogenic acid recovery } \\
\text { (mg CGA eq. Ig TS) }\end{array}$} & $\begin{array}{c}\text { Chlorogenic acid purity } \\
\text { (g CGA eq. /100 g TS extract) }\end{array}$ \\
\hline Assay & Time (min) & L/S ratio (mL/g TS) & Folin Ciocalteu & UV-Abs 325nm & Folin Ciocalteu & UV-Abs 325nm \\
\hline $\mathbf{1}$ & $10.0(-1)$ & $10.0(-1)$ & $35.9 \pm 0.4$ & $28.2 \pm 1.5$ & $32.2 \pm 1.4$ & $25.4 \pm 0.5$ \\
\hline $\mathbf{2}$ & $50.0(1)$ & $10.0(-1)$ & $38.4 \pm 0.7$ & $30.0 \pm 1.1$ & $32.8 \pm 0.5$ & $25.7 \pm 1.8$ \\
\hline $\mathbf{3}$ & $10.0(-1)$ & $40.0(1)$ & $45.6 \pm 0.4$ & $41.4 \pm 0.2$ & $34.4 \pm 0.1$ & $31.2 \pm 0.02$ \\
\hline $\mathbf{4}$ & $50.0(1)$ & $40.0(1)$ & $51.6 \pm 0.6$ & $45.3 \pm 0.5$ & $34.8 \pm 0.1$ & $30.5 \pm 0.5$ \\
\hline $\mathbf{5}$ & $1.7(-1.41)$ & $25.0(0)$ & $37.2 \pm 1.0$ & $28.7 \pm 0.6$ & $37.4 \pm 1.4$ & $28.8 \pm 1.0$ \\
\hline $\mathbf{6}$ & $58.3(1.41)$ & $25.0(0)$ & $52.3 \pm 1.2$ & $37.6 \pm 0.6$ & $37.7 \pm 0.8$ & $27.1 \pm 0.4$ \\
\hline $\mathbf{7}$ & $30.0(0)$ & $3.8(-1.41)$ & $30.2 \pm 0.1$ & $24.9 \pm 0.3$ & $31.9 \pm 0.7$ & $26.3 \pm 0.2$ \\
\hline $\mathbf{8}$ & $30.0(0)$ & $46.2(1.41)$ & $49.1 \pm 2.6$ & $45.0 \pm 2.1$ & $34.1 \pm 1.8$ & $31.3 \pm 1.5$ \\
\hline $\mathbf{9}$ & $30.0(0)$ & $25.0(0)$ & $48.9 \pm 1.7$ & $36.65 \pm 0.5$ & $35.7 \pm 1.7$ & $26.8 \pm 0.04$ \\
\hline $\mathbf{1 0}$ & $30.0(0)$ & $25.0(0)$ & $48.1 \pm 0.2$ & $36.2 \pm 1.05$ & $35.9 \pm 0.3$ & $27.0 \pm 0.6$ \\
\hline
\end{tabular}

The statistical analysis revealed that both the L/S ratio and the time were significant and exhibited a positive correlation with the recovery (Fig.3 A). For both determinations, the L/S ratio had more influence than the time on the ultimate recovery. Quadratic terms of these two variables were found to be significant when measured by the Folin method in opposition to UV-absorbance, where they were not. This was reflected in a linear or curved surface in the 3D surface plots (Fig. 4 A and B) and could be explained by an early extraction of other reducing compounds detected by Folin Ciocalteu method. According to these models, optimal values of time and ratio in terms of chlorogenic acid extraction would be situated at their maximums. Both models presented $\mathrm{R}^{2}$ adjusted higher than 0.9 (Fig. 4 A) (Appendix A Table A1 for statistical analysis report).

Similar observations were found in the other studies dedicated to phenols extraction from SCG, where both time and liquid-solid ratio were identified to be relevant $[16,18,21,22]$. Also coinciding with the 
observations of this study, the time was observed to have less influence on the final response in the study of Zuorro and Lavecchia [16].

The total yields obtained in this study (up to $52 \mathrm{mg} \mathrm{CGA} \mathrm{eq./g} \mathrm{TS)} \mathrm{are} \mathrm{higher} \mathrm{than} \mathrm{previously} \mathrm{reported} \mathrm{with}$ solid-liquid extraction of SCG (up to $28 \mathrm{mg}$ gallic acid equivalents /g TS [11]). Apart from the different experimental conditions, the difference could be also partially attributed to the use of different standards (chlorogenic acid gives higher signal than gallic acid, the most common standard for Folin Ciocalteu method [38]) or differences in SCG composition.

The quotient of the chlorogenic acid equivalents to the total solids present in the liquid extract gave the purity of the chlorogenic acid preparation. According to Folin Ciocalteu determinations all extracts would be over $30 \%$, but slightly under according to UV-Vis absorbance, which is actually the minimum concentration of CGA suitable for commercialization (SVAgrofood, personal communication). Both models identified just the L/S ratio be significant, where high ratios would favour the purity (Fig. 3 B). Noteworthy to say, these models presented lower $\mathrm{R}^{2}$ adjusted ( 0.66 and 0.81 respectively), and were thus not used for predictions.

\subsubsection{Economic estimation}

Up to this point, it had been observed that higher CGA recoveries were obtained at high L/S ratios and long extraction times. However fulfilling these conditions would increase the cost of the process (more solvent, higher energy demands and higher capital investments). In order to balance these factors, a rough economic estimation of the different experimental sets was performed and a 3D model was constructed (see section 2.3.2 for calculations). Taking into consideration the cost of the solvent and the energy needs of the extraction and evaporation steps and subtracting it from the expected income from the commercialization of the extract, the balance appeared to favour low L/S ratios of solvent (Fig. 4 C) (Appendix A Table A1 for statistical analysis report).

The conditions were fixed at the conditions maximizing the response (L/S ratio $10 \mathrm{~mL} / \mathrm{g}$ TS and time 40 min). Nevertheless, concentrations of ethanol lower than $60 \%$ should be tested in future research in order to further improve the economic feasibility of the extraction.

\subsubsection{Model validation}

The model validation at the chosen conditions $(10 \mathrm{~mL} / \mathrm{g}$ TS and a time of $40 \mathrm{~min})$ gave CGA recoveries in the range of the predicted confidence interval (Table 3), while the purity was slightly out of range, possibly due to the already mentioned lower R squared of the models. 


\subsubsection{Comparison with a commercial extract}

In order to further validate the nature of the extract obtained with the optimised conditions, it was compared to a commercial preparation by analysing the content of chlorogenic acid (Table 3). For the commercial extract, the two determination methods gave the same figure. Oppositely, in the extract obtained in this study the Folin Ciocalteu determinations gave higher results. This confirmed that the extract from spent coffee grounds contains reducing substances or antioxidants other than chlorogenic acids, i.e. melanoidins $[4,5]$, that interfere with the Folin determination and that are not present in the green coffee beans.

Table 3. Validation of the regression models with comparison between predicted and measured responses, and comparison with the commercial CGA extract.

\begin{tabular}{|c|cc|cc|}
\cline { 2 - 5 } \multicolumn{1}{c|}{} & \multicolumn{2}{c|}{ CGA recovery (mg CGA eq. /g TS) } & \multicolumn{2}{c|}{ CGA purity (CGA eq. /100 g TS) } \\
\cline { 2 - 5 } \multicolumn{1}{c|}{} & Folin Ciocalteu & UV-Abs 325 nm & Folin Ciocalteu & UV-Abs 325 nm \\
\hline Predicted & $39.4 \pm 2.1$ & $29.4 \pm 1.8$ & $33.4 \pm 1.3$ & $25.9 \pm 1.2$ \\
\hline Obtained response & $41.4 \pm 1.6$ & $29.3 \pm 2.3$ & $39.0 \pm 0.6$ & $27.6 \pm 1.0$ \\
\hline Commercial & & & $61.5 \pm 2.7$ & $61.7 \pm 1.1$ \\
\hline
\end{tabular}

Observing the UV-Vis profile (Fig. 5), the commercial extract had a much more similar shape to the pure chlorogenic acid than the extract obtained in this study, which had a prominent peak around $280 \mathrm{~nm}$. When caffeine was removed from the extract by chloroform extraction this peak was notably reduced and the extract reached $32.70 \%$ purity with a UV absorbance determination, the minimum purity for commercialisation. No chlorogenic acid was lost in the process (recovery of 104\%).

Removal of total solids from the extract could be suggested as an additional step in order to increase the purity in chlorogenic acid. Upgrading to 45\% CGA would give a higher value and more chances to compete with current extracts from green coffee beans, which are obtained at high purity and only require caffeine removal (SVAgrofood, personal communication). Nevertheless, a purification step might not be needed if, instead of looking just at the concentration of CGA, the activity of the extract as a whole is evaluated, given that compounds other than 5-CQA have been found to contribute to the effect of the dietary supplements. The main isomer found in green coffee beans, 5-CQA, is considerably isomerised during the roasting process into 3-CQA and 4-CQA [39]. In vitro studies reported in the patent of Svetol® [36] revealed that 3- and 4-CQA had more influence on the glucose regulation than 5-CQA and that the effect was not dose dependent. Moreover, other compounds formed during the roasting process such as melanoidins and chlorogenic acid lactones have also been described to have possible effects on sugar metabolism [40,41]. For all these reasons, even though the concentration of CGA is lower in the extract produced from spent coffee grounds, the presence of other substances could make it equally or even more effective. Thus, in vitro and in vivo tests with this product 
should be performed in order to evaluate its efficacy and potential to substitute current extracts from green coffee beans. These extracts are currently sold at around $\$ 40 / \mathrm{kg}$ which is about one thousand times higher price than ethanol. Thus, the inclusion of this high value product in the bioethanol production would greatly favour the economy of the process.

\subsection{Optimisation of the dilute sulphuric acid hydrolysis}

Although hydrolysis and fermentation yields were very high in the conditions tested in section 3.1 (Fig. 2 B), ethanol concentration represented only a $1.5 \%(\mathrm{v} / \mathrm{v})$ of the final broth. Distillation costs are known to be reduced exponentially with the increase in ethanol content, with $4 \%(\mathrm{v} / \mathrm{v})$ being a general threshold for an economically competitive process $[42,43]$. A strategy to overcome this problem would be to use higher concentration of solids in the hydrolysis, with the aim of increasing the sugar concentration and consequently the ethanol titer. With this in mind, dilute acid hydrolysis was evaluated on a 3-factor experimental design with L/S, time and acid concentration as factors (Table 4). The range of the values of the factors was set based on previous experience on the residue $[7,8]$ and common values reported thus far $[44,45]$. Regarding the liquidsolid ratio, L/S, the low range was fixed at $3.5 \mathrm{~g} / \mathrm{g}$ as lower values did not permit the recovery of the liquid after hydrolysis.

First evaluated responses were the sugar concentration in the hydrolysate and the efficiency of sugar release (Table 4). Glucose was just released in minor amounts, representing efficiencies between 1-15\%. Oppositely, arabinose was completely released in all the assays, even though the concentration was very low. Galactose was also almost completely released in all cases except the least severe conditions, and mannose release efficiencies ranged from 60 to $94 \%$. The results of the statistical analysis for each individual sugar can be found in appendix A.

A similar behaviour of the solubilisation of the different polymers was observed in [7]. Arabinose was the most easily released sugar. This monomer is in the form of side chains in the arabinogalactan and it is a wellknown that side chains are more easily broken than backbone structures [46]. At the same time, mannan backbone was more resistant to hydrolysis than galactan backbone of arabinogalactans as they are less branched and able to form crystalline structures similar to cellulose [47]. Low yields of glucose were anticipated given the well-known poor effectiveness of dilute acid hydrolysis over cellulose [46]. 
Burniol-Figols, A., Cenian, K., Skiadas, I. V., \& Gavala, H. N. (2016). Integration of chlorogenic acid recovery and bioethanol production from spent coffee grounds. Biochemical engineering journal, 116, 54-64.

Table 4. Experimental design of dilute acid hydrolysis with the real and coded values of the factors (Coded dimensionless values in parenthesis) and the results for the responses: sugar

concentration ( $\mathrm{g} / \mathrm{L}$ ) and efficiency of sugar release expressed as a percentage of the sugars present in the extracted solids SCGE. (Gluc: glucose; Man: mannose; Gal: galactose; Arab: arabinose; HMF: Hydroxymethylfurfural; CGA eq.: chlorogenic acid equivalents.)

\begin{tabular}{|c|c|c|c|c|c|c|c|c|c|c|c|c|c|c|c|c|c|c|}
\hline \multirow[b]{3}{*}{ Assay } & \multirow{2}{*}{\multicolumn{3}{|c|}{$\begin{array}{c}\text { Factors } \\
\text { Real value (coded value) }\end{array}$}} & \multicolumn{15}{|c|}{ Responses } \\
\hline & & & & \multicolumn{9}{|c|}{ Concentration (g/L) } & \multicolumn{6}{|c|}{ Efficiency of release (\%) } \\
\hline & $\begin{array}{l}\text { Time } \\
(\min )\end{array}$ & $\begin{array}{l}\text { L/S } \\
\text { ratio (g } \\
\text { liquid/g } \\
\text { TS) }\end{array}$ & $\begin{array}{l}\text { Acid } \\
\left(\mathrm{H}_{2} \mathrm{SO}_{4}\right. \\
\% \mathrm{w} / \mathrm{w})\end{array}$ & Gluc & Man & Gal & Arab & $\begin{array}{c}\text { C6 } \\
\text { sugars }\end{array}$ & Total sugars & Furfural ${ }^{*}$ & HMF* & $\begin{array}{l}\text { CGA } \\
\text { eq. }{ }^{*}\end{array}$ & Gluc & Man & Gal & Arab & $\begin{array}{c}\text { C6 } \\
\text { sugars }\end{array}$ & $\begin{array}{l}\text { Total } \\
\text { sugars }\end{array}$ \\
\hline 1 & $20(-1)$ & $3.5(-1)$ & $0.5(-1)$ & $0.3 \pm 0.3$ & $3.8 \pm 1.8$ & $4.4 \pm 0.5$ & $7.6 \pm 0.4$ & $8.4 \pm 1.6$ & $15.9 \pm 2$ & 0.23 & 0.00 & 2.08 & $1 \pm 1$ & $4 \pm 2$ & $13 \pm 1$ & $109 \pm 6$ & $6 \pm 1$ & $10 \pm 1$ \\
\hline 2 & $70(1)$ & $3.5(-1)$ & $0.5(-1)$ & $0.3 \pm 0.02$ & $11.4 \pm 0.1$ & $12.4 \pm 2.5$ & $7.7 \pm 0.2$ & $24.2 \pm 2.5$ & $31.8 \pm 2.6$ & 0.34 & 0.24 & 2.15 & $1 \pm 0.1$ & $13 \pm 0.1$ & $37 \pm 8$ & $111 \pm 3$ & $16 \pm 2$ & $20 \pm 2$ \\
\hline 3 & $20(-1)$ & $10(1)$ & $0.5(-1)$ & $0.2 \pm 0.1$ & $11.8 \pm 1.9$ & $9.2 \pm 1.6$ & $2.8 \pm 0.2$ & $21.2 \pm 3.4$ & $24 \pm 3.6$ & 0.11 & 0.01 & 1.02 & $2 \pm 1$ & $37 \pm 6$ & $79 \pm 14$ & $116 \pm 10$ & $40 \pm 6$ & $43 \pm 7$ \\
\hline 4 & $70(1)$ & $10(1)$ & $0.5(-1)$ & $0.4 \pm 0.1$ & $19.6 \pm 0.3$ & $13.2 \pm 0.5$ & $3.3 \pm 0.1$ & $33.2 \pm 0.3$ & $36.5 \pm 0.3$ & 0.14 & 0.24 & 1.10 & $4 \pm 1$ & $61 \pm 1$ & $113 \pm 4$ & $134 \pm 3$ & $62 \pm 0.2$ & $65 \pm 0.3$ \\
\hline 5 & $20(-1)$ & $3.5(-1)$ & $3.5(1)$ & $2 \pm 0.05$ & $69.6 \pm 0.3$ & $31.4 \pm 1.8$ & $7.6 \pm 0.3$ & $102.9 \pm 2.1$ & $110.5 \pm 2.4$ & 0.38 & 1.05 & 1.85 & $7 \pm 0.2$ & $75 \pm 0.3$ & $93 \pm 5$ & $108 \pm 4$ & $66 \pm 1$ & $68 \pm 1$ \\
\hline 6 & $70(1)$ & $3.5(-1)$ & $3.5(1)$ & $3.1 \pm 0.02$ & $73.9 \pm 2.8$ & $30.2 \pm 3$ & $7.1 \pm 0.05$ & $107.3 \pm 0.1$ & $114.4 \pm 0.2$ & 0.48 & 2.08 & 2.01 & $11 \pm 0$ & $80 \pm 3$ & $90 \pm 9$ & $100 \pm 1$ & $69 \pm 0.0$ & $70 \pm 0.0$ \\
\hline 7 & $20(-1)$ & $10(1)$ & $3.5(1)$ & $0.9 \pm 0.03$ & $28.4 \pm 2.5$ & $13.3 \pm 0.9$ & $3 \pm 0.3$ & $42.6 \pm 3.4$ & $45.6 \pm 3.7$ & 0.18 & 0.41 & 0.93 & $9 \pm 0.3$ & $87 \pm 8$ & $112 \pm 7$ & $120 \pm 12$ & $78 \pm 6$ & $80 \pm 7$ \\
\hline 8 & $70(1)$ & $10(1)$ & $3.5(1)$ & $1.5 \pm 0.03$ & $28.1 \pm 1.4$ & $12.2 \pm 0.2$ & $2.7 \pm 0.1$ & $41.8 \pm 1.1$ & $44.5 \pm 1.3$ & 0.23 & 0.65 & 1.01 & $15 \pm 0.3$ & $86 \pm 4$ & $103 \pm 2$ & $109 \pm 5$ & $77 \pm 2$ & $78 \pm 2$ \\
\hline 9 & $20(-1)$ & $6.75(0)$ & $2(0)$ & $0.9 \pm 0.02$ & $37.4 \pm 0.7$ & $19.4 \pm 2.6$ & $4.6 \pm 0.2$ & $57.6 \pm 1.9$ & $62.3 \pm 2$ & 0.20 & 0.37 & 1.23 & $6 \pm 0.1$ & $78 \pm 2$ & $112 \pm 15$ & $128 \pm 5$ & $72 \pm 2$ & $74 \pm 2$ \\
\hline 10 & $70(1)$ & $6.75(0)$ & $2(0)$ & $1.4 \pm 0.1$ & $44.8 \pm 2.0$ & $17.2 \pm 1.1$ & $4.3 \pm 0.04$ & $63.4 \pm 0.9$ & $67.7 \pm 1$ & 0.30 & 0.98 & 1.18 & $9 \pm 0.4$ & $94 \pm 4$ & $99 \pm 6$ & $120 \pm 1$ & $79 \pm 1$ & $81 \pm 1$ \\
\hline 11 & $45(0)$ & $3.5(-1)$ & $2(0)$ & $1.7 \pm 0.1$ & $62.3 \pm 0.01$ & $32.1 \pm 3.0$ & $7.7 \pm 0.3$ & $96.1 \pm 3.1$ & $103.8 \pm 3.4$ & 0.40 & 1.30 & 1.99 & $6 \pm 0.5$ & $68 \pm 0$ & $96 \pm 9$ & $110 \pm 4$ & $62 \pm 2$ & $64 \pm 2$ \\
\hline 12 & $45(0)$ & $10(1)$ & $2(0)$ & $0.8 \pm 0.1$ & $27.6 \pm 2.2$ & $13.6 \pm 1.6$ & $3 \pm 0.3$ & $42.1 \pm 3.8$ & $45.2 \pm 4.1$ & 0.19 & 0.51 & 0.89 & $8 \pm 1$ & $86 \pm 7$ & $116 \pm 13$ & $124 \pm 12$ & $78 \pm 7$ & $80 \pm 7$ \\
\hline 13 & $45(0)$ & $6.75(0)$ & $0.5(-1)$ & $0.5 \pm 0.01$ & $15.5 \pm 1.5$ & $15.9 \pm 1$ & $4.3 \pm 0.1$ & $31.9 \pm 0.5$ & $36.2 \pm 0.5$ & 0.20 & 0.11 & 1.30 & $3 \pm 0.1$ & $33 \pm 3$ & $92 \pm 6$ & $119 \pm 2$ & $40 \pm 1$ & $44 \pm 1$ \\
\hline 14 & $45(0)$ & $6.75(0)$ & $3.5(1)$ & $1.6 \pm 0.03$ & $37.9 \pm 1.2$ & $17.6 \pm 0.4$ & $3.8 \pm 0.04$ & $57.1 \pm 0.8$ & $60.9 \pm 0.8$ & 0.38 & 0.79 & 1.12 & $10 \pm 0.2$ & $79 \pm 3$ & $101 \pm 2$ & $105 \pm 1$ & $71 \pm 1$ & $72 \pm 1$ \\
\hline 15 & $45(0)$ & $6.75(0)$ & $2(0)$ & $1.1 \pm 0.1$ & $37 \pm 0.5$ & $18.2 \pm 0.1$ & $4.1 \pm 0.1$ & $56.3 \pm 0.5$ & $60.4 \pm 0.6$ & 0.30 & 0.71 & 1.08 & $7 \pm 0.3$ & $77 \pm 1$ & $105 \pm$ & $113 \pm 2$ & $70 \pm 1$ & $72 \pm 1$ \\
\hline 16 & $45(0)$ & $6.75(0)$ & $2(0)$ & $1.2 \pm 0.1$ & $39.6 \pm 3.1$ & $19.8 \pm 1.7$ & $4.4 \pm 0.4$ & $60.6 \pm 4.9$ & $65 \pm 5.3$ & 0.27 & 0.72 & 1.17 & $8 \pm 1$ & $83 \pm 6$ & $114 \pm 10$ & $121 \pm 12$ & $76 \pm 6$ & $78 \pm 6$ \\
\hline
\end{tabular}

*Standard deviations of furfural, HMF and CGA eq. were $<0.1 \mathrm{~g}$. 
Burniol-Figols, A., Cenian, K., Skiadas, I. V., \& Gavala, H. N. (2016). Integration of chlorogenic acid recovery and bioethanol production from spent coffee grounds. Biochemical engineering journal, 116, 54-64.

The total sugar concentration reached maximum values in the assays with more sever conditions of time and acid concentration and the lowest ratio of L/S, with a figure of $114 \mathrm{~g} / \mathrm{L}$, which represented a 3 times more concentrated hydrolysate compared to the one obtained in section $3.1(35 \mathrm{~g} / \mathrm{L})$. Total sugars efficiency values though, never surpassed $80 \%$, due to the low glucose release.

Concentrations of C6 sugars (hexoses), which are the fermentable sugars by S. cerevisiae and thus the ones subjective to optimisation, reached up to $107 \mathrm{~g} / \mathrm{L}$ with efficiencies ranging from 8 to $78 \%$ (Table 4). In terms of concentration, statistical analysis revealed that the acid concentration had a higher effect than the L/S ratio to the response (Fig. 6). The time had no significant influence. The C6 sugars concentration reached its maximum at a narrow region corresponding to maximum acid concentration and lowest ratio (Fig. 7 A). Fig. 7 B shows the poor influence of the time.

One main difference was observed when comparing the results for the efficiency response to the ones obtained in terms of concentration. The coefficient of the L/S ratio had a positive value, indicating that lower values had a negative impact on the efficiency (Fig. 6 Fig. 7 D). The time was significant, but had a very little influence on the final response (Fig. 6 and Fig. 7 E). (Appendix A Table A2 for statistical analysis report).

The results obtained here are, at a first glance, not in agreement with the only study analysing the influence of the different factors on dilute sulphuric acid of SCG [7]. That study, identified the temperature and the reaction time as the only significant factors influencing the sugar release efficiency, discarding the effect of the liquid-solid ratio and the acid dose. It has to be noted though, that the L/S ratio was studied at a much higher range (10-14 g/g) and the acid concentration was expressed as $\mathrm{mg}$ acid/g of TS, giving different concentrations of acid depending on the substrate and the L/S ratio. The neutral influence of the time here could be explained by the equipment used, which had a heating and cooling ramp of around 30 minutes, making the reaction time more diffuse. Hence, conclusions are not incompatible. Nevertheless, this factor should be further evaluating before further process design and up-scaling.

During dilute acid hydrolysis, the sugars can undergo certain modifications: pentose and hexose sugars can form furfural and hydroxymethylfurfural (HMF) respectively, both cyclic compounds with known inhibitory effects [48]. These compounds were also evaluated in the different hydrolysis scenarios (Table 4).

Concentration of HMF was always higher than of furfural, which could be easily explained by the higher proportion of C6 sugars compared to C5 sugars. The values observed, between 0.5 and $2 \mathrm{~g} / \mathrm{L}$ for HMF, are in the low range of values found in dilute acid hydrolysates $[34,49,50]$. Based on the same references, concentrations of furfural between 0.1 and $0.48 \mathrm{~g} / \mathrm{L}$ measured in this study should not have a serious impact. 
Burniol-Figols, A., Cenian, K., Skiadas, I. V., \& Gavala, H. N. (2016). Integration of chlorogenic acid recovery and bioethanol production from spent coffee grounds. Biochemical engineering journal, 116, 54-64.

Statistical analysis of HMF revealed that the time had a more important effect on HMF than for sugars concentrations (Fig. 7 C). Hence, low times would be recommended to avoid problems in fermentation without compromising the sugar concentration. Also, the phenolic compounds (Table 4) reached their maximum concentration of $2 \mathrm{~g} / \mathrm{L}$ in the samples with the lowest L/S ratio. Given that a concentration of around $4 \mathrm{~g} / \mathrm{L}$ did not exhibit any significant inhibition effect (section 3.1), those values were not considered problematic for the fermentation.

\subsubsection{Economic estimation}

One of the main objectives of this study was to evaluate whether a lower amount of dilute acid solution could lead to a higher concentration of sugars without compromising the efficiency of the process, with the ultimate objective of lowering the costs of the process. The results showed that concentration of sugars did increase, but there was a negative effect on the efficiency. In order to find the balance between these two responses, an economical estimation of the effect of the L/S ratio was performed for each one of the experimental points and a 3D model was calculated.

In the context of an ethanol production plant, a low L/S ratio would be translated at a lower cost of the hydrolysis and fermentation reactors and a decreased cost of the distillation. On the other hand, an increased efficiency would lead to a higher ethanol yield from a given raw material.

Fig. $7 \mathrm{~F}$ displays a 3D surface representing the balance between the potential incomes coming from ethanol production and the costs of the hydrolysis reactor in the context of a soluble coffee factory with an annual production of 25550 tonnes (see section 2.3.2 for calculations). Just with this rough calculation, the increased costs derived from a high volume of liquid (high L/S) countervailed the losses of the lower efficiency, yielding the best results at the lowest value of ratio (3.5 g liquid/g TS). Although the real optimal ratio would be probably out of the studied region, values lower than 3.5 created operational problems in labscale due to the high concentration of solids.

The balance was negative for high values of L/S ratio and low acid concentrations (Fig. 7 F). In those cases, the calculated costs of the process would be too high compared to the income derived from the ethanol commercialisation. This fact reflected the low trade value of ethanol as a bulk chemical and how sensitive the profitability can be in respect to changes of the process conditions. A big difference in the scale can be observed when comparing this graph to Fig. 4 C, where balances for chlorogenic acid, a high value product, were always positive. 
It is important to emphasise though, that this study aimed to find rational values to use in the following steps and does not aim at providing a detailed economic estimation of the costs of ethanol production. A more accurate analysis should study the fermentability of each one of the hydrolysates and use the overall ethanol productivity as final response. Moreover, the increased maintenance costs derived from increased acid concentration and distillation costs should also be taken into account.

As the acid concentration was not included in the economic estimation, the regression fixed the optimal concentration at $3 \%(\mathrm{w} / \mathrm{w})$, which is the one maximizing the efficiency at a ratio of $3.5 \mathrm{~g}$ liquid/g TS. The time was fixed at 20 minutes due to the effect on HMF concentration.

\subsubsection{Model validation}

A validation of the model was carried out at the chosen conditions (3.5 g liquid/g TS, $3 \% \mathrm{H}_{2} \mathrm{SO}_{4}(\mathrm{w} / \mathrm{w}$ ) and 20 minutes) maintaining the same scale as in the experimental design runs (10 $\mathrm{g}$ of acid solution). In general, results showed a good agreement between predicted and observed responses, with all values being within the confidence interval given by the model (Table 5).

The same conditions were also applied at a slightly higher scale (200 g of liquid) in order to proceed with the study of the fermentability of the hydrolysate. In this case, lower efficiencies were obtained, with the fermentable sugar concentration thus decreasing considerably - from $98.78 \mathrm{~g} / \mathrm{L}$ to $88.95 \mathrm{~g} / \mathrm{L}$. This could be attributed to potential changes in the heating dynamics.

Table 5. Validation of the regression models with comparison between predicted and measured responses.

\begin{tabular}{|c|c|c|c|}
\hline & Predicted responses & Obtained responses (10g) & Obtained responses $(200 \mathrm{~g})$ \\
\hline Total sugars concentration (g/L) & $106.0 \pm 8.0$ & $104.5 \pm 2.9$ & $96.8 \pm 1.3$ \\
\hline C6 sugars concentration (g/L) & $99.4 \pm 8.7$ & $96.9 \pm 2.7$ & $88.95 \pm 0.4$ \\
\hline Total sugars release efficiency (\%) & $70.8 \pm 4.8$ & $72.5 \pm 2.0$ & $63.55 \pm 0.3$ \\
\hline C6 sugars release efficiency (\%) & $67.1 \pm 4.5$ & $70.1 \pm 1.9$ & $60.9 \pm 0.3$ \\
\hline
\end{tabular}

Despite the decrease in the expected sugars concentration and the decreased efficiency due to high concentration of solids, the final concentration of sugars, $95.38 \mathrm{~g} / \mathrm{L}$, was almost three times higher than with the initial conditions (35 g/L- Fig. $2 \mathrm{~B}$ ) . Moreover, this value is much higher than the $50 \mathrm{~g} / \mathrm{L}$ and $58 \mathrm{~g} / \mathrm{L}$ obtained in previous studies performing dilute acid hydrolysis of SCG $[8,14]$, and also higher than when dilute acid hydrolysis was combined with enzymatic hydrolysis of glucose (83.5 g/L) [8]. 


\subsection{Fementability of the high concentrated hydrolysate}

The hydrolysate obtained with the optimised conditions, from now on referred as high concentrated hydrolysate (HC_H), was fermented in S. cerevisiae in order to rule out any inhibitory effect. The ethanol productivities, yields and sugars $\%$ consumption were approximately the same as those obtained before the statistical optimisation (low concentrated hydrolysate (LC_H) (Table 6). Thus, not any apparent inhibitory effect was observed.

All sugars were completely metabolised and a preference of mannose over galactose became evident (Fig. 8 A). Ethanol concentration reached $39 \mathrm{~g} / \mathrm{L}(3,89 \% \mathrm{v} / \mathrm{v})$, which is, to the extent of our knowledge, the highest value obtained with SCG (a maximum of $22 \mathrm{~g} / \mathrm{L}$ was obtained in the [8]). Moreover, the ethanol concentration in the effluent reached almost $4 \%$ (Table 6), which is considered as the feasibility threshold for the posterior distillation step $[42,43]$.

\subsubsection{Inclusion of solids in the fermentation}

Mass balances performed during the solid-liquid separation after the hydrolysis (Table 6) showed that a big fraction of the hydrolysate was retained in the solids, reducing thus considerably the overall efficiency of the process. This phenomenon was especially noteworthy in the case of the high concentrated hydrolysate, where $66 \%$ of the hydrolysate remained in the solid fraction. Consequently, slurry fermentations including the solids after the hydrolysis were tested with the two hydrolysis conditions studied here (Fig. 8 B and C).

While the inclusion of solids in the low concentrated hydrolysate (LC_S) presented the same yields and rates as the liquid fermentation, the high concentrated slurry (HC_S) presented considerable differences with the liquid fermentation (Table 6). Time of fermentation (determined according to the halt in gas production) increased from 3 days to 9 days, due to an important initial lag phase and a general reduction in reaction rates. A big fraction of the sugars (especially galactose) remained unmetabolised. Moreover, the setting presented serious viscosity problems due to the high concentration of solids in the fermentation.

As a matter of fact, water insoluble solids (WIS) represented a $15.7 \%(\mathrm{w} / \mathrm{w})$ and it is a well-known fact that fermentations with WIS higher than 10\% exhibit fermentation challenges, mainly attributed to the higher presence of inhibitors and viscosity problems $[42,51,52]$. Here, the detrimental effect of inhibitors was ruled out by the good performance of the fermentation without solids $\left(\mathrm{HC} \_\mathrm{H}\right)$. Thus, rheology problems are likely to be responsible; however, they could be overcome with improved mixing systems.

Despite the fact that the best ethanol concentration was obtained using only the liquid in the fermentation (HC_L), the overall analysis of the bioprocess pointed out the low efficiency of the overall process (18.0\%), 
mainly due to an important loss of hydrolysate in the solid-liquid separation (Table 6). The incorporation of the solids, despite the low sugar consumption, increased this value to $41.7 \%$, a number that would increase to $56.8 \%$ if the same sugar consumption as in the hydrolysate was attained. Moreover, this scenario supports the possibility of applying cellulases and performing simultaneous saccharification and fermentation to release glucose monomers and take advantage of the cellulose fraction as well.

Table 6. Overall balance of hydrolysis and fermentation. LC_H: Low concentrated hydrolysate; LC_S: Low concentrated slurry; HC_H: High concentrated hydrolysate; HC_S; High concentrated slurry.

\begin{tabular}{|c|cccc|}
\cline { 2 - 5 } \multicolumn{1}{c|}{} & LC_H & LC_S & HC_H & HC_S \\
\hline Total sugars hydrolysis efficiency & 80.6 & 80.6 & 63.6 & 63.6 \\
\hline Solid/liquid separation efficiency (\%) & 60.4 & - & 34.0 & - \\
\hline Water insoluble solids (WIS) (\% w/w) & - & 9.0 & - & 15.7 \\
\hline Ethanol concentration (g/L) & 17.4 & 17.4 & 39.2 & 29.6 \\
\hline Productivity (g/L/h) & 0.69 & 0.69 & 0.77 & 0.18 \\
\hline Ethanol yield (\%) $^{\mathbf{a}}$ & 97.8 & 96.0 & 90.9 & 97.6 \\
\hline Sugar consumption (\%) & 90.6 & 91.9 & 91.6 & 67.2 \\
\hline Ethanol effluent (\% w/v) $^{\text {(\%) }}$ & 1.74 & 1.74 & 3.92 & 2.96 \\
\hline Ethanol yield (L/Kg SCG) & 0.28 & 0.47 & 0.13 & 0.28 \\
\hline Overall process efficiency (\%) & 43.1 & 71.1 & 18.0 & 41.7 \\
\hline
\end{tabular}

${ }^{\mathrm{a} C}$ Considering in the yield of $\mathrm{g}$ ethanol $/ \mathrm{g}$ sugar consumed and a theoretical yield of $0.51 \mathrm{~g} / \mathrm{g}$ as $100 \%$.

${ }^{b}$ Considering the total sugar content of $\mathrm{SCG}^{\mathrm{E}}$ and a complete conversion of sugars to ethanol with a yield of $0.51 \mathrm{~g} / \mathrm{g}$ as $100 \%$.

\section{Conclusions}

A biorefinery delivering chlorogenic acid and bioethanol from spent coffee grounds was proposed within this study. Chlorogenic acid extraction prior to acid hydrolysis benefited the subsequent dilute acid hydrolysis step by increasing the percentage of sugars in the solids and the sugar release efficiency. Overall, extraction of phenolics enhanced the breakdown of polymers with no loss of soluble sugars, which is precisely the desired effect in a biorefinery concept.

The two main steps of the process, the phenolics extraction and the dilute acid hydrolysis, were studied by experimental design methodology with both the efficiency of the processes and the economic feasibility to be considered as responses for the statistical models. Inclusion of the economic aspect was proved to be critical as in both statistical designs low L/S ratios affected negatively the efficiency but exhibited better economic performance. Thus, economic considerations at early stages of process development can help towards the design of an economically competitive process.

For the phenolics extraction, optimal conditions were a liquid-solid ratio of $10 \mathrm{~mL} / \mathrm{g}$ TS and a time of 40 min, which resulted in an extract of $32 \%$ chlorogenic acid after caffeine extraction. This extract reached thus a 
minimum purity to be able to enter the market as a replacement for current extracts produced from green

coffee beans, a product with a high trade value.

Optimal conditions for the dilute acid hydrolysis were a liquid-solid ratio of $3.5 \mathrm{~g} / \mathrm{g} \mathrm{TS}, 3 \%(\mathrm{w} / \mathrm{w}) \mathrm{H}_{2} \mathrm{SO}_{4}$ and $20 \mathrm{~min}$. With these conditions applied ethanol concentration of $3.9 \%(\mathrm{v} / \mathrm{v})$ was obtained in the fermented hydrolysate, which is very close to the $4 \%$ threshold generally considered for an economically feasible distillation. Inclusion of the solids in the fermentation showed the potential of further increasing the overall efficiency of the process by a factor of 2-3.

\section{Appendix A. Report of the statistical analysis.}

Supplementary data and figures about the models obtained with the statistical analysis.

\section{Acknowledgements}

The authors would like to thank Aalborg University for providing financial and technical support for this research. In addition, they would like to thank Lotte Vaa and Edyta Kowalczyk for their participation in the initial stages.

\section{References}

[1] ICO (International Coffee Organisation), Trade Statistics Tables. Total production by exporting countries, (2014). www.ico.org/prices/po-production.pdf (accessed December 17, 2015).

[2] S.I. Mussatto, E.M.S. Machado, S. Martins, J. a. Teixeira, Production, Composition, and Application of Coffee and Its Industrial Residues, Food Bioprocess Technol. 4 (2011) 661-672.

[3] M. a. Silva, S. a. Nebra, M.J. Machado Silva, C.G. Sanchez, The use of biomass residues in the Brazilian soluble coffee industry, Biomass and Bioenergy. 14 (1998) 457-467.

[4] R. Campos-Vega, G. Loarca-Piña, H. Vergara-Castañeda, B.D. Oomah, Spent coffee grounds: A review on current research and future prospects, Trends Food Sci. Technol. 45 (2015) 24-36.

[5] A.S.P. Moreira, F.M. Nunes, M.R. Domingues, M.A. Coimbra, Coffee melanoidins: structures, mechanisms of formation and potential health impacts, Food Funct. 3 (2012) 903-915.

[6] A.G.W. Bradbury, D.J. Halliday, Chemical structures of green coffee bean polysaccharides, J. Agric. Food Chem. 38 (1990) 389-392.

[7] S.I. Mussatto, L.M. Carneiro, J.P. a Silva, I.C. Roberto, J. a. Teixeira, A study on chemical constituents and sugars extraction from spent coffee grounds, Carbohydr. Polym. 83 (2011) 368-374.

[8] E.E. Kwon, H. Yi, Y.J. Jeon, Sequential co-production of biodiesel and bioethanol with spent coffee grounds, Bioresour. Technol. 136 (2013) 475-480.

[9] R. Cruz, M.M. Cardoso, L. Fernandes, M. Oliveira, E. Mendes, P. Baptista, et al., Espresso coffee residues: A valuable source of unextracted compounds, J. Agric. Food Chem. 60 (2012) 7777-7784.

[10] A. Farah, C.M. Donangelo, Phenolic compounds in coffee, Braz. J. Plant Physiol. 18 (2006) 23-36.

[11] A. Panusa, A. Zuorro, R. Lavecchia, G. Marrosu, R. Petrucci, D. Farmaco, et al., Recovery of Natural Antioxidants from Spent Coffee Grounds, J. Agric. Food Chem. 61 (2013) 4162-4168.

[12] K. Ramalakshmi, I.R. Kubra, L.J.M. Rao, Physicochemical characteristics of green coffee: Comparison of graded and defective beans, J. Food Sci. 72 (2007).

[13] I.S. Choi, S.G. Wi, S.B. Kim, H.J. Bae, Conversion of coffee residue waste into bioethanol with using popping pretreatment, Bioresour. Technol. 125 (2012) 132-137.

[14] S.I. Mussatto, E.M.S. Machado, L.M. Carneiro, J.A. Teixeira, Sugars metabolism and ethanol production by different yeast strains from coffee industry wastes hydrolysates, Appl. Energy. 92 (2012) 763-768.

[15] M.V.P. Rocha, L.J.B.L. de Matos, L.P. De Lima, P.M.D.S. Figueiredo, I.L. Lucena, F.A.N. Fernandes, 
et al., Ultrasound-assisted production of biodiesel and ethanol from spent coffee grounds, Bioresour. Technol. 167 (2014) 343-348.

[16] A. Zuorro, R. Lavecchia, Spent coffee grounds as a valuable source of phenolic compounds and bioenergy, J. Clean. Prod. 34 (2012) 49-56.

[17] I. Onakpoya, R. Terry, E. Ernst, The use of green coffee extract as a weight loss supplement: A systematic review and meta-analysis of randomised clinical trials, Gastroenterol. Res. Pract. 2011 (2011).

[18] S.I. Mussatto, L.F. Ballesteros, S. Martins, J.A. Teixeira, Extraction of antioxidant phenolic compounds from spent coffee grounds, Sep. Purif. Technol. 83 (2011) 173-179.

[19] M. Pinelo, A.G. Tress, M. Pedersen, A. Arnous, A.S. Meyer, Effect of Cellulases, Solvent Type and Particle Size Distribution on the Extraction of Chlorogenic Acid and Other Phenols from Spent Coffee Grounds, Am. J. Food Technol. 2 (2007) 641-651.

[20] J. Bravo, C. Monente, I. Juániz, M.P. De Peña, C. Cid, Influence of extraction process on antioxidant capacity of spent coffee, Food Res. Int. 50 (2011) 610-616.

[21] A. Zuorro, Optimization of polyphenol recovery from espresso coffee residues using factorial design and response surface methodology, Sep. Purif. Technol. 152 (2015) 64-69.

[22] A. Zuorro, R. Lavecchia, Polyphenols and energy recovery from spent coffee grounds, 25 (2011) 285290.

[23] M. Ranic, M. Nikolic, M. Pavlovic, A. Buntic, S. Siler-Marinkovic, S. Dimitrijevic-Brankovic, Optimization of microwave-assisted extraction of natural antioxidants from spent espresso coffee grounds by response surface methodology, J. Clean. Prod. 80 (2014) 69-79.

[24] A. Sluiter, B. Hames, D. Hyman, C. Payne, R. Ruiz, C. Scarlata, et al., Determination of Total Solids in Biomass and Total Dissolved Solids in Liquid Process Samples, Natl. Renew. Energy Lab. (2008).

[25] A. Sluiter, B. Hames, R. Ruiz, C. Scarlata, J. Sluiter, D. Templeton, et al., Determination of Structural Carbohydrates and Lignin in Biomass, Natl. Renew. Energy Lab. (2011).

[26] A.B. Bjerre, A. Plöger, T. Simonsen, A. Woidemann, A.S. Schmidt, Quantification of solubilized hemicellulose from pretreated lignocellulose by acid hydrolysis and high-performance liquid chromatography, Risø Natl. Lab. Roskilde, Denmark. (1996).

[27] G.N. Baroi, I. Baumann, P. Westermann, H.N. Gavala, Butyric acid fermentation from pretreated and hydrolysed wheat straw by an adapted C lostridium tyrobutyricum strain, Microb. Biotechnol. 8 (2015) 874-882.

[28] L. Dao, M. Friedman, Chlorogenic Acid Content of Fresh and Processed Potatoes Determined by Ultraviolet Spectrophotometry, J. Agric. Food Chem. 40 (1992) 2152-2156.

[29] K.H. Esbensen, D. Guyot, F. Westad, L.P. Houmoller, Multivariate Data Analysis - in Practice: An Introduction to Multivariate Data Analysis and Experimental Design, 5th ed., Aalborg Univeristy Esbjerg, 2010.

[30] EIA (U.S. Energy Information Administration), Transportation: Ethanol wholesale price, (2015). http://www.eia.gov/oiaf/aeo/tablebrowser/\#release=AEO2014ER\&subject=0-AEO2014ER\&table=12AEO2014ER\&region=0-0\&cases=full2013-d102312a, ref2014er-d102413a (accessed December 17, 2015).

[31] EIA (U.S. Energy Information Administration), International Energy statistics- Brazil., (2015). http://www.eia.gov/beta/international/analysis.cfm?iso=BRA (accessed December 12, 2015).

[32] EIA (U.S. Energy Information Administration), Spot prices. Crude oil and petroleum products, (2015). http://www.eia.gov/dnav/pet/pet_pri_spt_s1_a.htm (accessed December 15, 2015).

[33] R.J. Wooley, M.F. Ruth, J. Sheenhan, K. Ibsen, H. Majdeski, A. Galvez, Lignocellulosic Biomass to Ethanol Process Design and Economics Utilizing Co-current Dilute Acid Prehydrolysis and Enzymatic Hydrolysis Current and Futuristic Scenarios, Natl. Renew. Energy Lab. (1999).

[34] J.R. Almeida, T. Modig, A. Petersson, B. Hähn-Hägerdal, G. Lidén, M.F. Gorwa-Grauslund, Increased tolerance and conversion of inhibitors in lignocellulosic hydrolysates by Saccharomyces cerevisiae, J. Chem. Technol. Biotechnol. 82 (2007) 340-349.

[35] S. Muthuswamy, H.P. V. Rupasinghe, Fruit phenolics as natural antimicrobial agents: Selective antimicrobial activity of catechin, chlorogenic acid and phloridizin, J. Food, Agric. Environ. 5 (2007) 8185.

[36] A. Ibarra, M. Roller, J. Dikansky, Effects of a Decaffeinated Green Coffee Extract on Body Weight Control by Regulation of Glucose Metabolism, US 2011/0223281 A1, 2011.

[37] P.S. Murthy, M.M. Naidu, Recovery of Phenolic Antioxidants and Functional Compounds from Coffee Industry By-Products, Food Bioprocess Technol. 5 (2012) 897-903.

[38] O.K. Chun, D. Kim, Consideration on equivalent chemicals in total phenolic assay of chlorogenic acidrich plums, Food Res. Int. 37 (2004) 337-342.

[39] A. Farah, T. De Paulis, L.C. Trugo, P.R. Martin, Effect of roasting on the formation of chlorogenic acid 
lactones in coffee, J. Agric. Food Chem. 53 (2005) 1505-1513.

[40] J. Shearer, A. Farah, T. de Paulis, D.P. Bracy, R.R. Pencek, T.E. Graham, et al., Quinides of roasted coffee enhance insulin action in conscious rats., J. Nutr. 133 (2003) 3529-3532.

[41] R.C. Borrelli, A. Visconti, C. Mennella, M. Anese, V. Fogliano, Chemical characterization and antioxidant properties of coffee melanoidins, J. Agric. Food Chem. 50 (2002) 6527-6533.

[42] R. Koppram, E. Tomás-Pejó, C. Xiros, L. Olsson, Lignocellulosic ethanol production at high-gravity: Challenges and perspectives, Trends Biotechnol. 32 (2014) 46-53.

[43] G. Zacchi, a Axelsson, Economic evaluation of preconcentration in production of ethanol from dilute sugar solutions., Biotechnol. Bioeng. 34 (1989) 223-233.

[44] N. Mosier, C. Wyman, B. Dale, R. Elander, Y.Y. Lee, M. Holtzapple, et al., Features of promising technologies for pretreatment of lignocellulosic biomass, Bioresour. Technol. 96 (2005) 673-686.

[45] A.K. Chandel, F.A.F. Antunes, P.V. De Arruda, T.S.S. Milessi, S.S. Silva, M.G.A. Felipe, Dilute Acid Hydrolysis of Agro-Residues for the Depolymerization of Hemicellulose: State-of-the-Art, in: D-Xylitol, Springer-Verlag Berlin Heidelberg, 2012: pp. 39-61.

[46] A.T.W.M. Hendriks, G. Zeeman, Pretreatments to enhance the digestibility of lignocellulosic biomass, Bioresour. Technol. 100 (2009) 10-18.

[47] A. Ebringerová, H. Thomas, Hemicellulose, Adv Polym Sci. 186 (2005) 1-67.

[48] E. Palmqvist, B. Hahn-Hägerdal, Fermentation of lignocellulosic hydrolysates. II: Inhibitors and mechanisms of inhibition, Bioresour. Technol. 74 (2000) 25-33.

[49] M.J. Taherzadeh, R. Eklund, L. Gustafsson, C. Niklasson, G. Lidén, Characterization and fermentation of dilute-acid hydrolyzates from wood, Ind. Eng. Chem. Res. 36 (1997) 4659-4665.

[50] S. Larsson, E. Palmqvist, B. Hahn-Hägerdal, C. Tengborg, K. Stenberg, G. Zacchi, et al., The generation of fermentation inhibitors during dilute acid hydrolysis of softwood, Enzyme Microb. Technol. 24 (1999) 151-159.

[51] K. Hoyer, M. Galbe, G. Zacchi, Production of fuel ethanol from softwood by simultaneous saccharification and fermentation at high dry matter content, J. Chem. Technol. Biotechnol. 84 (2009) 570-577.

[52] K. Olofsson, M. Bertilsson, G. Lidén, A short review on SSF - an interesting process option for ethanol production from lignocellulosic feedstocks., Biotechnol. Biofuels. 1 (2008) 7. 


\section{Figures}

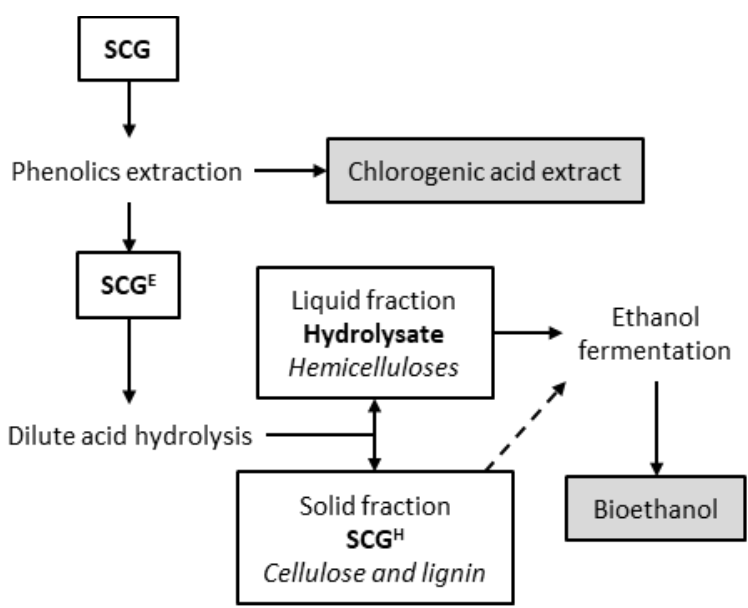

Fig. 1. Process scheme. Spent coffee grounds (SCG) were used for phenolics extraction obtaining a liquid chlorogenic acid extract. The solids (SCGE) were then treated with dilute sulphuric acid hydrolysis and the liquid hydrolysate was used in ethanol fermentation. Solids after dilute acid hydrolysis $\left(\mathrm{SCG}^{\mathrm{H}}\right)$ were incorporated in the fermentation in some of the experiments, denominated slurry fermentations. 


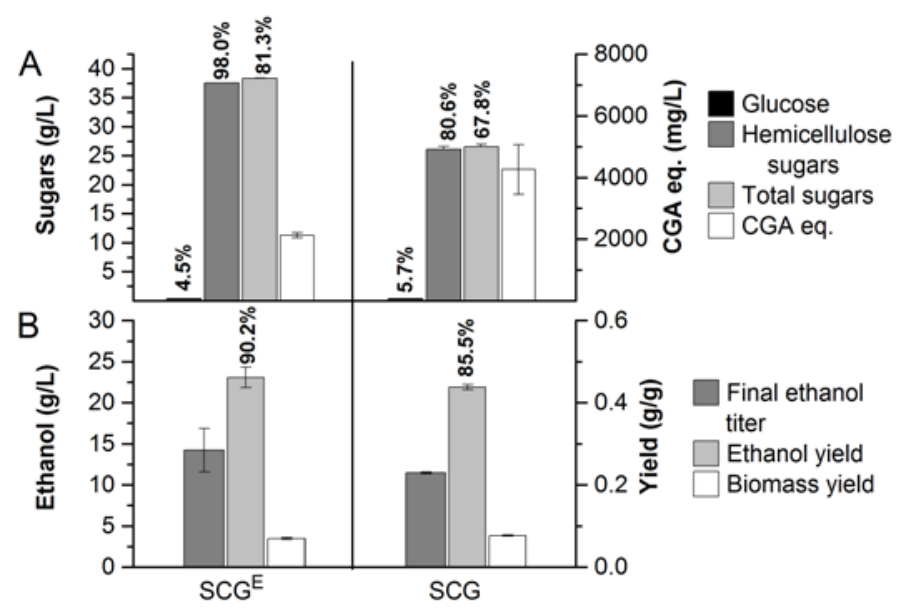

Fig. 2. (A) Concentration of sugars and chlorogenic acid equivalents (CGA eq.) in the hydrolysates obtained with ethanol extracted (SCGE) and non-extracted SCG. Figures on top of the bars represent efficiency of hydrolysis (\%). (B) Ethanol yield ( $\mathrm{g}$ ethanol produced /g sugars consumed) and biomass yield ( $\mathrm{g}$ TSS produced /g sugars consumed). Percentage on top of bars represent the percentage of the theoretical ethanol yield $(0.51 \mathrm{~g} / \mathrm{g})$. 


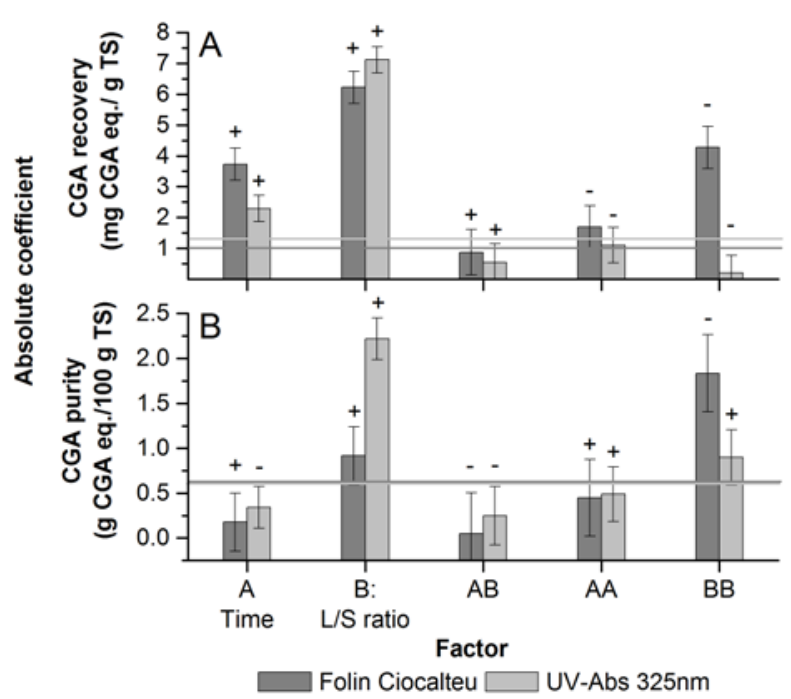

Fig. 3. Coded coefficients of the regression analysis, representing the absolute influence of each one of the factors on the responses, (A) CGA recovery efficiency and (B) CGA purity of the extract, both measured by Folin Ciocalteu method and by UV-absorbance at $325 \mathrm{~nm}$. Bars over the line represent significant terms $(p<0.05)$ and $+/$ - symbols on top of the bars stand for the sign of the coefficient. 

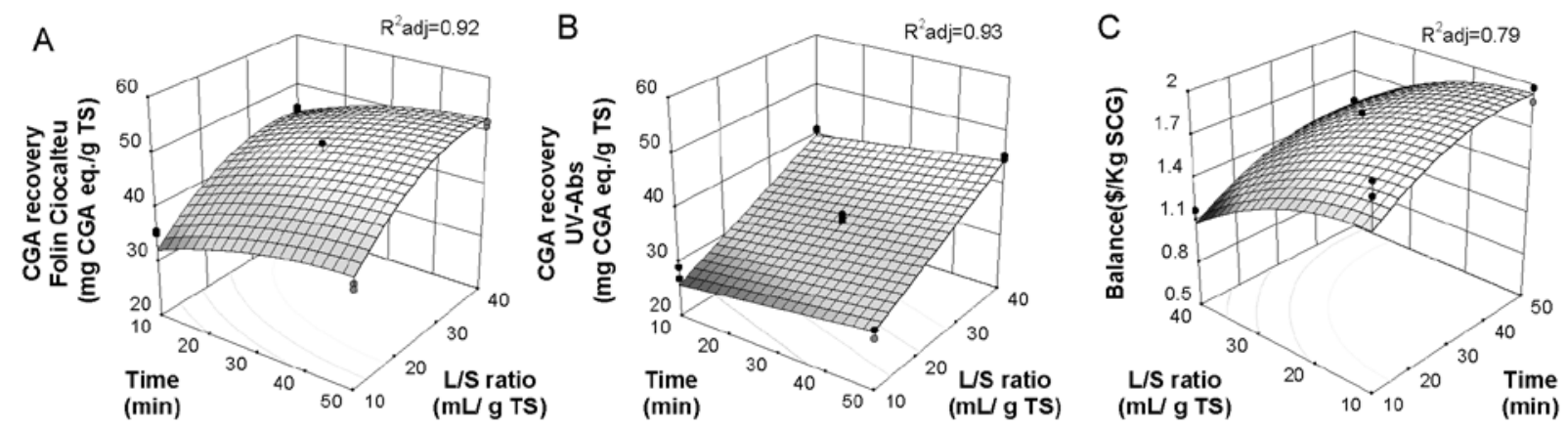

Fig. 4. Three-dimensional surface plots of the regression equations obtained with the acid hydrolysis statistical design. Responses are as follows: Recovery of chlorogenic acid equivalents measured by Folin Ciocalteu method (A) and by UV absorbance at $325 \mathrm{~nm}$ (B) and economic balance (C). 


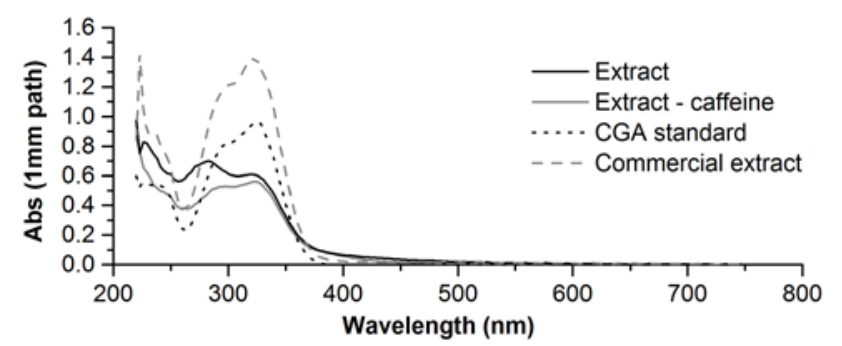

Fig. 5. UV-Vis absorbance profile of: the extract obtained in the validation of the experimental design, the same extract after caffeine removal with chloroform, pure chlorogenic acid standard (5-O-caffeoylquinic acid) and the commercial preparation of Svetol®. 


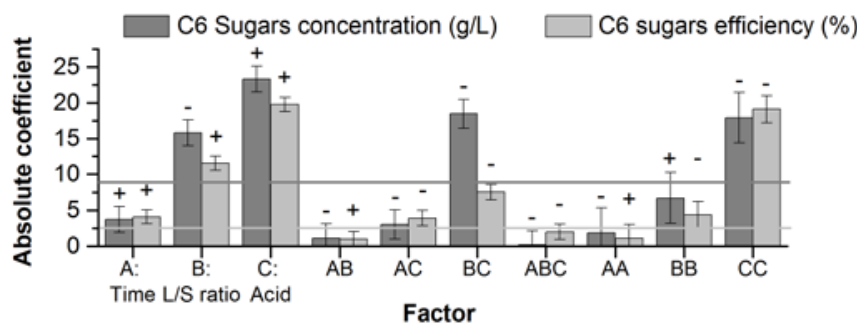

Fig. 6. Coded coefficients of the regression analysis representing the absolute influence of each one of the factors in the $\mathrm{C} 6$ sugars concentration $(\mathrm{g} / \mathrm{L})$ and in the sugar release efficiency $(\%)$. Bars over the line represent significant terms $(p<0.05)$ and $+/$ - symbols on top of the bars stand for the sign of the coefficient. 

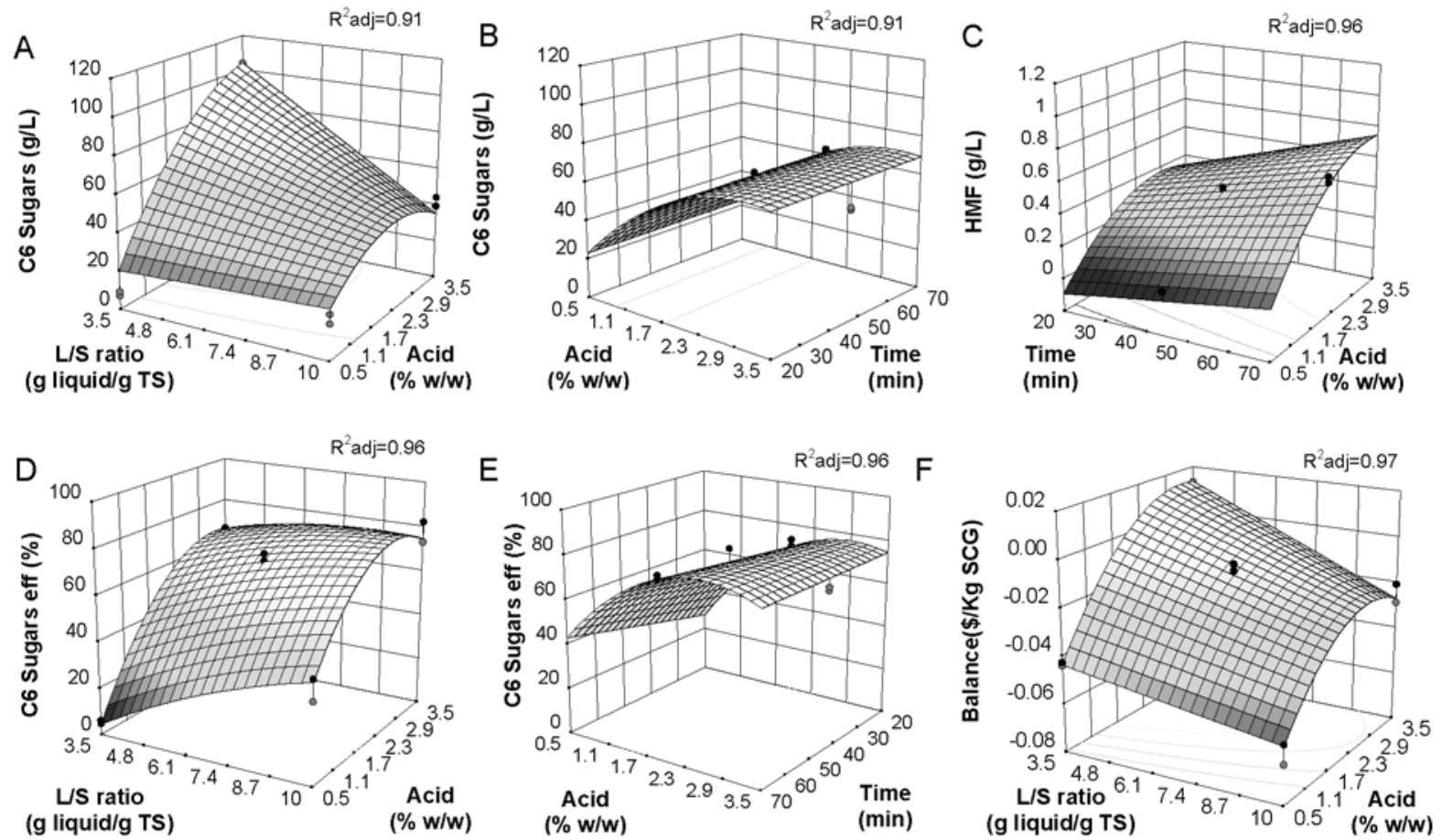

Fig. 7. Three-dimensional surface plots of the regression equations obtained with the acid hydrolysis statistical design. Responses are as follows: (A and B) C6 sugars concentration, (C) hydroxymethylfurfural concentration, (D and E) C6 release efficiency and (F) economic balance. A, D and F: ratio vs. acid concentration with a fix time of 45 min. B, C and E: acid concentration vs. time with a fixed ratio of $6.75 \mathrm{~g}$ liquid/g TS. 


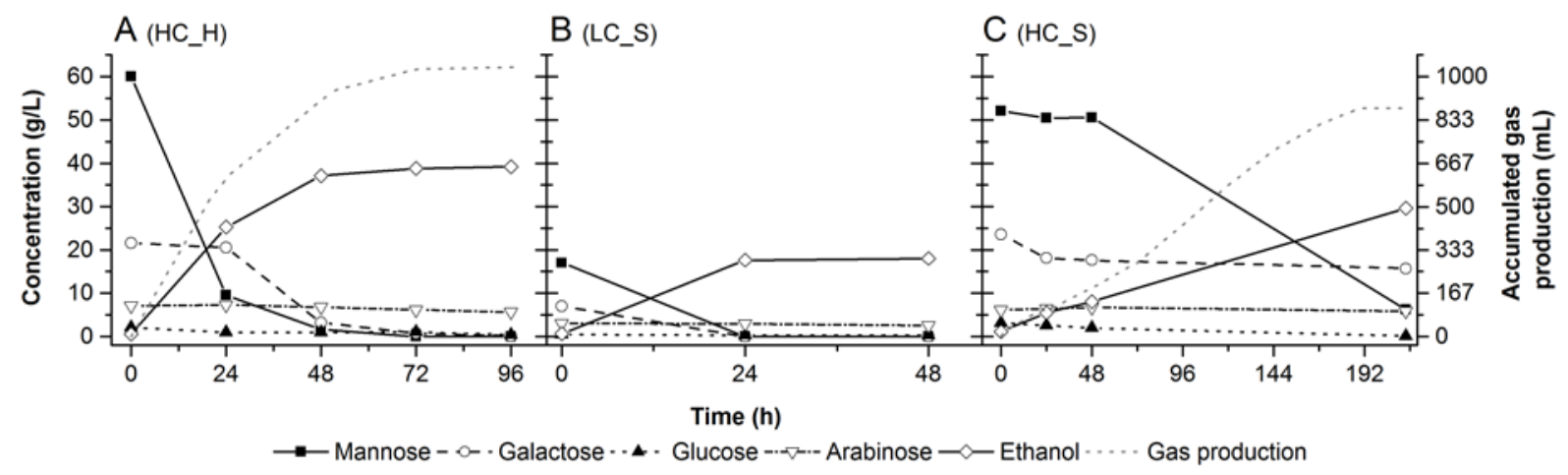

Fig. 8. Sugars consumption, ethanol, and accumulated gas production during the fermentation of the (A): High concentrated hydrolysate (HC_H), (B): Low concentrated slurry (LC_S), (C): High concentrated slurry (HC_S). 


\section{Appendix A. Report of the statistical analysis}

The material presented in these supplementary materials is meant to support the different statistical analysis presented in the manuscript, providing more information about the coefficients of the regression equation and the model fit analysis.

Table A1 reports information about the statistical analysis of the phenolics extraction, corresponding to the section 3.2 of the manuscript. Tables A2 and A3 correspond to the statistical analysis of the dilute acid hydrolysis (section 3.3). More specifically Table A2 reports the results of the models used in the discussion of results and Table A3 reports results of the models for the individual sugars. The last were not used for predictions as the objective of the optimization was the C6 sugars, but are presented for extra information to the reader. The three-dimensional surface plots for the individual sugars are presented in Figure A1 and A2.

Table A1. Results from statistical analysis of the phenolics extraction optimization, with coded and actual coefficients and model fit analysis of the regression equations of statistically significant factors $(p<0.05)$

\begin{tabular}{|c|c|c|c|c|c|}
\hline \multirow[b]{2}{*}{ Coded coefficients $^{a}$} & \multicolumn{2}{|c|}{ Efficiency (mg CGA eq./mg TS) } & \multicolumn{2}{|c|}{ Purity (g CGA eq./100 g TS) } & \multirow{2}{*}{$\begin{array}{c}\text { Economic } \\
\text { balance (\$/Kg } \\
\text { SCG) }\end{array}$} \\
\hline & Folin Ciocalteu & UV-Abs & Folin Ciocalteu & UV-Abs & \\
\hline Constant & 48.49 & 35.40 & 36.31 & 27.46 & 1.737 \\
\hline A: time & 3.73 & 2.29 & & & 0.182 \\
\hline B: ratio & 6.22 & 7.11 & 0.92 & 2.22 & -0.252 \\
\hline \multicolumn{6}{|l|}{$A B$} \\
\hline AA & -1.69 & & & & -0.124 \\
\hline BB & -4.27 & & -1.84 & 0.90 & -0.119 \\
\hline \multicolumn{6}{|l|}{ Actual coefficients $^{a}$} \\
\hline Constant & 16.84 & 20.10 & 29.15 & 25.68 & 1.27 \\
\hline A: Time (min) & 0.44 & 0.11 & & & 0.028 \\
\hline B: Ratio (mL/g TS) & 1.36 & 0.47 & 0.51 & -0.0053 & 0.010 \\
\hline \multicolumn{6}{|l|}{$A B$} \\
\hline AA & -0.0042 & & & & -0.00031 \\
\hline BB & -0.019 & & -0.0090 & -0.0031 & -0.00053 \\
\hline \multicolumn{6}{|l|}{ Model fit ${ }^{b}$} \\
\hline $\mathbf{R}^{2}$ & 0.938 & 0.941 & 0.697 & 0.836 & 0.838 \\
\hline$R^{2}$ adj & 0.922 & 0.934 & 0.662 & 0.817 & 0.794 \\
\hline $\mathbf{R}^{2}$ pred & 0.887 & 0.916 & 0.561 & 0.761 & 0.709 \\
\hline Std. Dev. (RMSE) & 2.11 & 1.81 & 1.23 & 0.99 & 0.14 \\
\hline Model $p$-value & $<0.001$ & $<0.001$ & $<0.001$ & $<0.001$ & $<0.001$ \\
\hline
\end{tabular}

${ }^{\mathrm{a} C o d e d ~ c o e f f i c i e n t s ~ a r e ~ t o ~ b e ~ a p p l i e d ~ w i t h ~ t h e ~ f a c t o r s ~ i n ~ d i m e n s i o n l e s s ~ u n i t s ~(-1 ~ t o ~+1) ~ w h i l e ~ a c t u a l ~ c o e f f i c i e n t s ~ a r e ~ t o ~ b e ~ a p p l i e d ~ w i t h ~ t h e ~}$ factors in the original units.

${ }^{\mathrm{b}}$ Model fit analysis: $\mathrm{R}^{2}$ (R-squared); $\mathrm{R}^{2}$ adj (R-squared adjusted); $\mathrm{R}^{2}$ pred (R-squared prediction); standard deviation and model $p$-value. 
Table A2. Results from statistical analysis of the dilute acid hydrolysis, with coded and actual coefficients and model fit analysis of the regression equations of statistically significant factors $(p<0.05)$. Responses include:

C6 sugars, Total sugars, hydroxymethylfurfural (HMF) and economic balance.

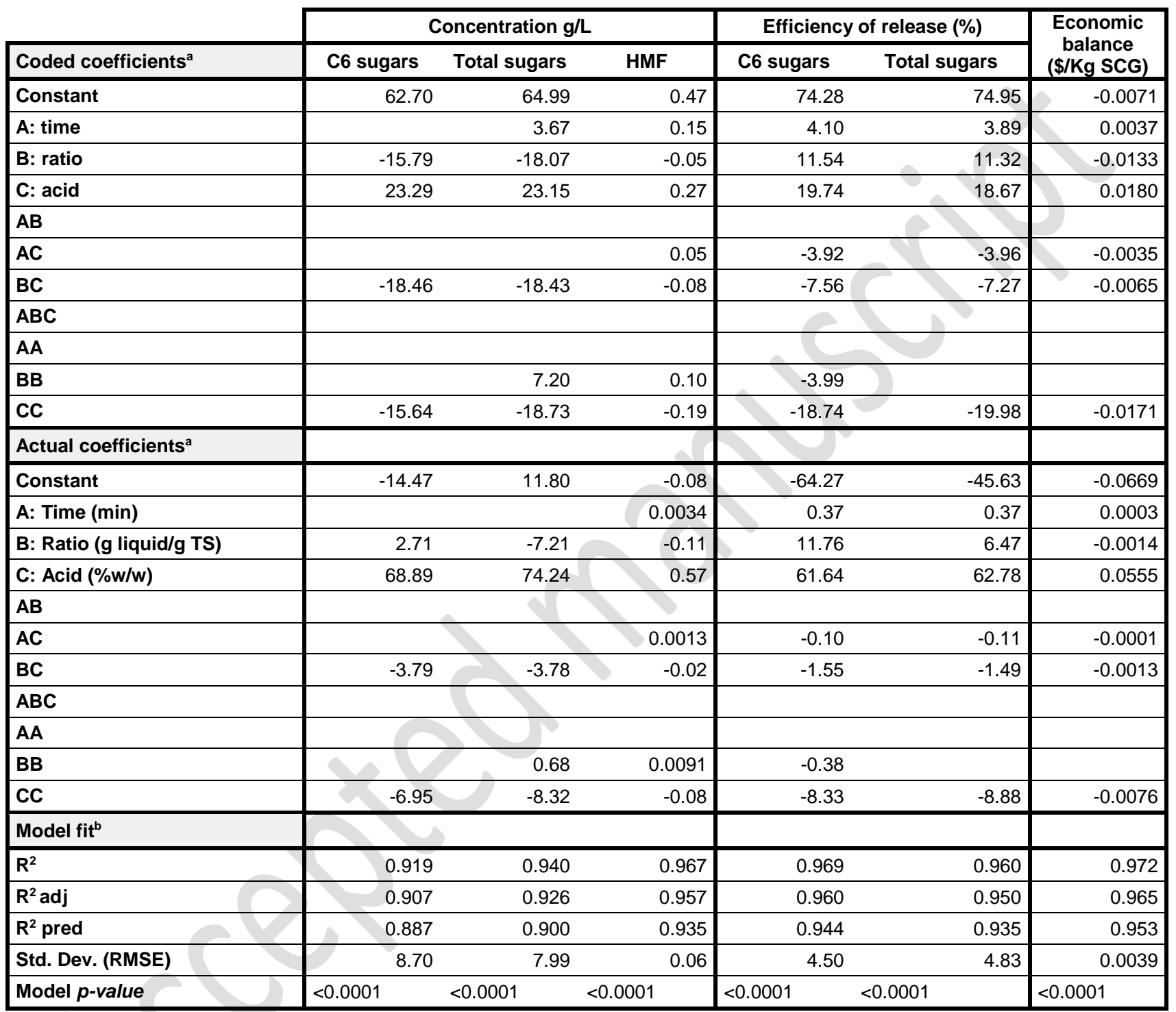

${ }^{a}$ Coded coefficients are to be applied with the factors in dimensionless units $(-1$ to +1$)$ while actual coefficients are to be applied with the factors in the original units.

${ }^{b}$ Model fit analysis: $\mathrm{R}^{2}$ (R-squared); $\mathrm{R}^{2}$ adj (R-squared adjusted); $\mathrm{R}^{2}$ pred (R-squared prediction); standard deviation and model $p$-value. 
Table A3. Results from statistical analysis of the dilute acid hydrolysis, with coded and actual coefficients and model fit analysis of the regression equations of statistically significant factors $(p<0.05)$. Responses are the individual sugars analysed: Glucose, Mannose, Galactose and Arabinose (concentration and efficiency).

\begin{tabular}{|c|c|c|c|c|c|c|c|c|}
\hline \multirow[b]{2}{*}{ Coded coefficients $^{a}$} & \multicolumn{4}{|c|}{ Concentration g/L } & \multicolumn{4}{|c|}{ Efficiency of release (\%) } \\
\hline & Glucose & Mannose & Galactose & Arabinose & Glucose & Mannose & Galactose & Arabinose $^{c}$ \\
\hline Constant & 1.11 & 39.92 & 20.05 & 4.33 & 7.67 & 80.97 & 107.02 & \\
\hline A: time & 0.26 & 2.69 & & & 1.59 & 5.16 & & \\
\hline B: ratio & -0.35 & -10.55 & -4.89 & -2.28 & 1.25 & 11.84 & 19.56 & \\
\hline C: acid & 0.74 & 17.57 & 4.98 & -0.15 & 4.04 & 25.87 & 16.35 & \\
\hline$A B$ & & & & & 0.47 & 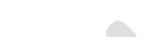 & 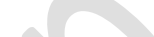 & D \\
\hline AC & 0.20 & & & & 1.096 & -3.68 & 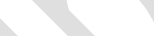 & \\
\hline BC & -0.33 & -12.91 & -5.21 & & 0.31 & -7.83 & -13.55 & \\
\hline \multicolumn{9}{|l|}{$A B C$} \\
\hline AA & & & & & & 4.71 & & \\
\hline BB & & 4.65 & & 1.08 & -0.61 & -4.57 & & \\
\hline CC & & -13.63 & -4.08 & -0.23 & -0.88 & -25.65 & -23.60 & \\
\hline \multicolumn{9}{|l|}{ Actual coefficients ${ }^{a}$} \\
\hline Constant & -0.04 & -6.37 & 1.90 & 13.51 & -2.12 & -68.00 & -34.89 & \\
\hline A: Time (min) & -0.0005 & 0.11 & & s & -0.03 & -0.28 & & \\
\hline B: Ratio (g liquid/g TS) & 0.028 & -3.89 & 0.63 & -2.08 & 0.78 & 12.70 & 11.58 & \\
\hline C: Acid (\%w/w) & 0.71 & 53.83 & 17.78 & 0.30 & 2.52 & 78.10 & 71.62 & \\
\hline$A B$ & & & & & 0.0058 & & & \\
\hline$A C$ & 0.005 & & 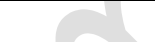 & & 0.03 & -0.098 & & \\
\hline BC & -0.07 & -2.65 & -1.07 & 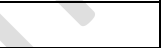 & 0.06 & -1.61 & -2.78 & \\
\hline \multicolumn{9}{|l|}{ ABC } \\
\hline$A A$ & & 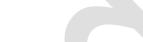 & 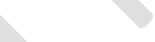 & & & 0.0075 & & \\
\hline BB & & 0.44 & & 0.102 & -0.06 & -0.43 & & \\
\hline CC & & -6.06 & -1.81 & -0.100 & -0.39 & -11.40 & -10.49 & \\
\hline \multicolumn{9}{|l|}{ Model fit ${ }^{b}$} \\
\hline $\mathbf{R}^{2}$ & 0.963 & 0.957 & 0.808 & 0.985 & 0.986 & 0.977 & 0.793 & 0.525 \\
\hline$R^{2}$ adj & 0.956 & 0.947 & 0.779 & 0.982 & 0.981 & 0.968 & 0.762 & 0.434 \\
\hline R2 pred & 0.941 & 0.929 & 0.729 & 0.979 & 0.969 & 0.953 & 0.703 & 0.275 \\
\hline Std. Dev. (RMSE) & 0.16 & 4.72 & 3.68 & 0.25 & 0.53 & 4.89 & 13.96 & 7.48 \\
\hline Model $p$-value & $<0.0001$ & $<0.0001$ & $<0.0001$ & $<0.0001$ & $<0.0001$ & $<0.0001$ & $<0.0001$ & \\
\hline
\end{tabular}

${ }^{a}$ Coded coefficients are to be applied with the factors in dimensionless units $(-1$ to +1$)$ while actual coefficients are to be applied with the factors in the original units.

${ }^{b}$ Model fit analysis: $R^{2}$ (R-squared); $R^{2}$ adj (R-squared adjusted); $R^{2}$ pred (R-squared prediction); standard deviation and model $p$-value. ${ }^{c}$ Coefficients for the regression equation of arabinose efficiency are not presented due to the low quality of the model fit parameters. 

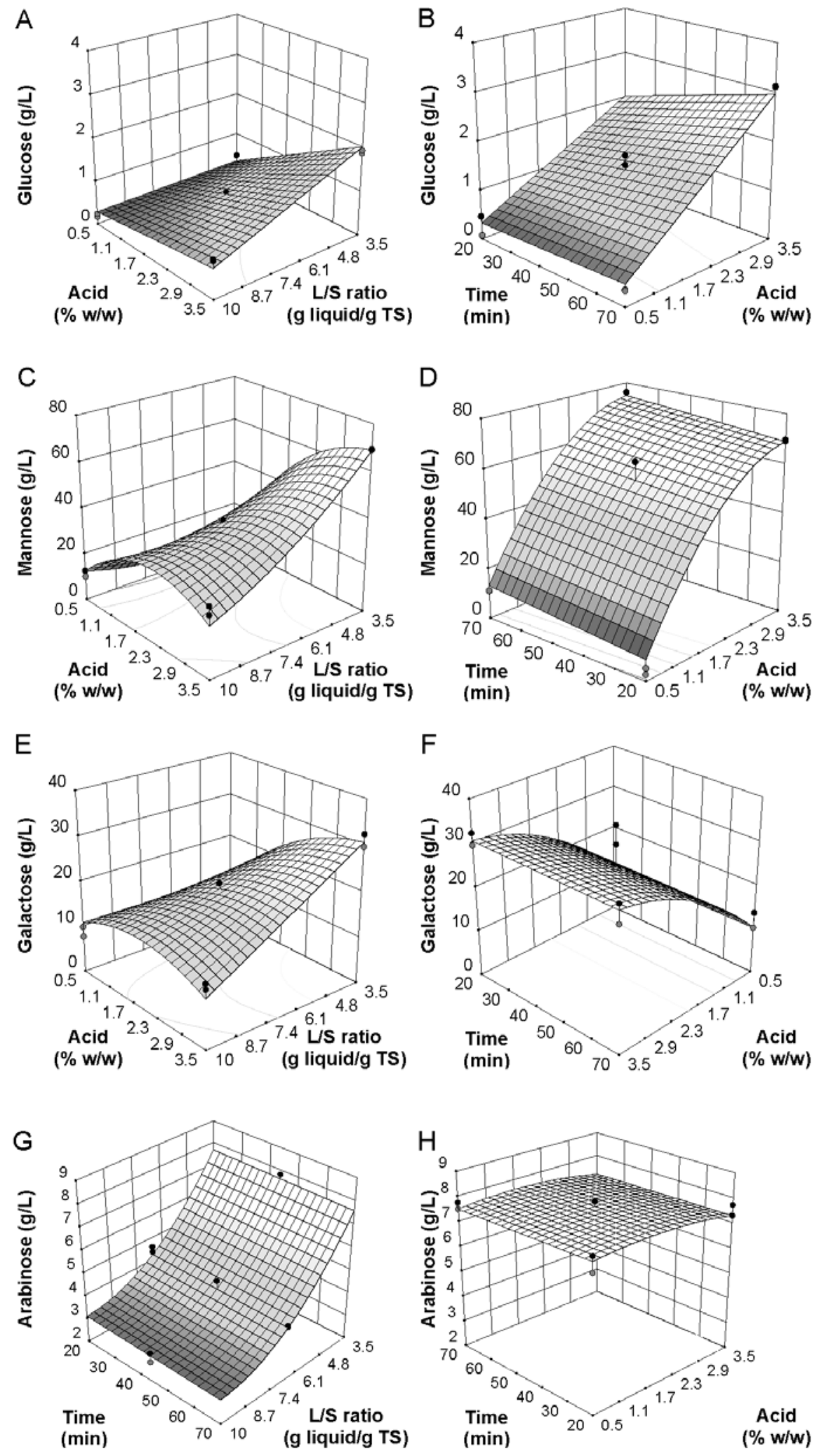

Fig. A1. Three-dimensional surface plots of the regression equations of concentration of the different sugar monomers in the hydrolysates. $\mathbf{A}, \mathbf{C}$ and $\mathbf{E}$ : ratio vs. acid concentration with a fix time of $20 \mathrm{~min} . \mathbf{B}, \mathbf{D}, \mathbf{F}$ and H: fixed L/S ratio of $3.5 \mathrm{~g}$ liquid/g TS. G: Fix acid of $2 \%$ (w/w). $\mathrm{R}^{2}$ adj: Glucose: 0.96; Mannose: 0.95; Galactose: 0.78; Arabinose:0.98. 

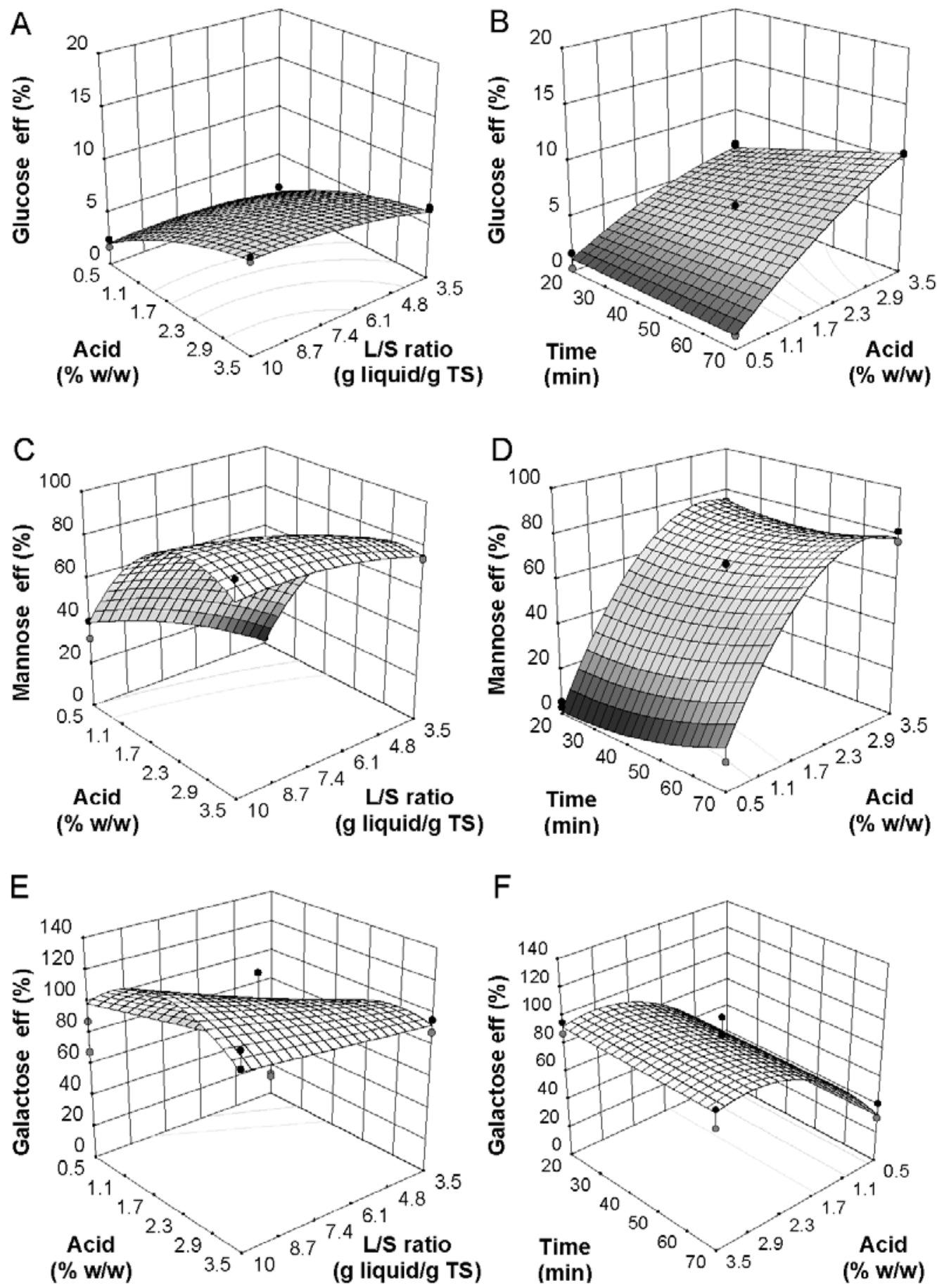

Fig. A2: Three-dimensional surface plots of the regression equations of efficiency of release of the different sugar monomers in the hydrolysates. A, C and E: fix time of $20 \mathrm{~min}$. B, D and F: fixed L/S ratio of $3.5 \mathrm{~g}$ liquid/g TS. R² adj: Glucose: 0.98; Mannose: 0.97; Galactose: 0.76. 